\title{
REVIEW ARTICLE OPEN Molecular mechanisms and clinical management of cancer bone metastasis
}

\author{
Manni Wang ${ }^{1}$, Fan $\mathrm{Xia}^{2}$, Yuquan $\mathrm{Wei}^{1}$ and Xiawei Wei ${ }^{1}$
}

As one of the most common metastatic sites of malignancies, bone has a unique microenvironment that allows metastatic tumor cells to grow and flourish. The fenestrated capillaries in the bone, bone matrix, and bone cells, including osteoblasts and osteoclasts, together maintain the homeostasis of the bone microenvironment. In contrast, tumor-derived factors act on bone components, leading to subsequent bone resorption or excessive bone formation. The various pathways involved also provide multiple targets for therapeutic strategies against bone metastases. In this review, we summarize the current understanding of the mechanism of bone metastases. Based on the general process of bone metastases, we specifically highlight the complex crosstalk between tumor cells and the bone microenvironment and the current management of cancer bone metastases.

Bone Research (2020)8:30 ; https://doi.org/10.1038/s41413-020-00105-1

\section{INTRODUCTION}

The distant metastasis of cancer cells has long been known to have characteristic preferences. ${ }^{1,2}$ Bone is one of the most common metastatic sites for malignancies, such as breast, prostate, and lung cancer. ${ }^{3}$ Bone metastases can be categorized into osteolytic metastases with bone resorption, osteoblastic metastases with excessive bone formation, and a mixed phenotype of both. 4,5 According to the "seed and soil" hypothesis, bone metastasis is dependent on the interactions between tumor cells and the bone microenvironment. The preferential colonization of tumor cells to bone partly relies on the fenestrated capillaries in bone, bone matrix, and cells in the bone marrow (BM) stroma, such as osteoblasts and osteoclasts. ${ }^{6-10}$ These components together maintain the homeostasis of the bone microenvironment. Several deleterious complications, such as ostealgia, fractures, serious hypercalcemia, and nerve compression syndromes, occur in bone metastasis. ${ }^{11}$ As recent advances in bone metastasis research have revealed various pathways involved in this process, both in the primary tumor site and in the resident bone microenvironment, we herein describe the current understanding of the mechanism for bone metastases. Based on the general process of bone metastases, we specifically highlight the complex crosstalk between tumor cells and the bone microenvironment.

\section{BONE MICROENVIRONMENT}

Tumor metastasis is a complex process that involves the reciprocal interactions between tumor cells and the bone microenvironment. The preferential tumor metastasis to bone is therefore probably attributed to the bone microenvironment, which corresponds to the "seed and soil" hypothesis described below. $^{12}$ The bone matrix, BM sinusoid capillaries with a fenestrated structure that provides an abundant blood supply, and the cells in the BM stroma such as osteoblasts and osteoclasts all contribute to the bone microenvironment. ${ }^{7,10}$ Therefore, elucidation of the composition of the bone microenvironment and its interaction with cancer cells can help clarify the underlying mechanisms of metastatic organotropism. The constant remodeling of the bone microenvironment is another potential reason for the preference of circulating tumor cells to colonize bones, and the regulation of cytokines and hormones during this process will be discussed herein.

\section{The premetastatic niche}

The premetastatic niche refers to the supportive environment of potential metastatic sites before the arrival of cancer cells, providing a fertile "soil" to facilitate the invasion, localization, survival, and proliferation of the "seeds," namely, metastatic tumor cells. ${ }^{12,13}$ In recent decades, studies on the selective colonization of cancer cells to bone have been primarily based on the "seed and soil" theory. ${ }^{14-16}$ First proposed by Steven Paget, this theory was based on the autopsy analysis of 735 breast cancer patients and was published in the Lancet in 1889. Intrinsic differences, such as the genomic composition of tumor cells, are primarily attributed to the proliferative phenotype and metastatic potential of the "seeds," but the microenvironmental condition of the host tissues, or the "soil," is equally important. The premetastatic niche can be formed even before tumor dissemination due to the tumor-derived factors released from primary tumors. ${ }^{17}$ These factors include several growth factors, such as vascular endothelial growth factor (VEGF). Moreover, the formation of a premetastatic niche relies on a suppressive immune system. Primary tumors recruit myeloid cells, which then allow tumor cells to evade

\footnotetext{
'Laboratory of Aging Research and Cancer Drug Targets, State Key Laboratory of Biotherapy and Cancer Center, National Clinical Research Center for Geriatrics, West China Hospital, Sichuan University, No. 17, Block 3, Southern Renmin Road, Chengdu 610041 Sichuan, P.R. China and ${ }^{2}$ Department of Neurosurgery, West China Hospital, Sichuan University, Chengdu 610041 Sichuan, P.R. China

Correspondence: Xiawei Wei (xiaweiwei@scu.edu.cn)

These authors contributed equally: Manni Wang and Fan Xia
}

Received: 30 May 2019 Revised: 3 September 2019 Accepted: 23 October 2019

Published online: 29 July 2020 
immune surveillance, leading to metastasis. ${ }^{18,19}$ Chemokines facilitate the recruitment of BM-derived cells (BMDCs) and the related immune evasion of primary tumor cells.

BMDCs

$\mathrm{BM}$ is a complex system consisting of multifunctional cells, including hematopoietic and mesenchymal stem cells (MSCs). ${ }^{20}$ The mobilized and recruited BMDCs, as well as other stromal cells, together create a premetastatic niche by releasing various growth factors, inflammatory cytokines and chemokines, and proangiogenic molecules to support tumor cell colonization. ${ }^{21,22}$ Recent studies have identified a subset of nonmalignant BM-derived hematopoietic progenitor cells (HPCs) that express VEGF receptor1 (VEGFR-1) and promote the arrival of metastatic tumor cells at distant sites. ${ }^{23}$ In response to primary tumor-derived chemokines, VEGFR-1 + BMDCs proliferate in the bloodstream and then preferentially localize to fibronectin-rich areas. At distant premetastatic sites, VEGFR-1 + HPCs upregulate the expression of the very late antigen-4 ligand, which specifically adheres to the newly synthesized fibronectin to establish a fibronectin-rich local microenvironment for cellular cluster formation. ${ }^{13}$ These studies revealed that BM-derived HPCs could help prepare the premetastatic site for tumor metastasis. VEGFR-1 + BMDCs, fibronectin, and associated stromal cells also promote the secretion of other chemokines, such as stromal cell-derived factor-1 (SDF-1), and altogether reshape the bone microenvironment for the colonization, survival, and growth of metastatic tumor cells. ${ }^{23,24}$

\section{Osteocytes}

In addition to osteoblasts and osteoclasts, which we will describe later in this review, osteocytes are a major cell type involved in the regulation of bone modeling and remodeling. ${ }^{25}$ Osteocytes are abundant in the calcified bone matrix and have a unique structure that allows them to interconnect with each other, osteoclasts, and BM cells through dendritic processes. ${ }^{26}$ This highly interconnected network allows the exchange of nutrients and metabolites of bone cells and the transport of assorted factors from osteocytes. Factors produced by osteocytes include sclerostin (SOST) $)^{27}$ as well as receptor activator of nuclear factor-kappa $B$ ligand (RANKL), ${ }^{28,29}$ dentin matrix acidic phosphoprotein $1,{ }^{30}$ and $\beta$-catenin, ${ }^{31}$ which modulate bone formation and resorption, especially in response to mechanical stimuli. Osteocytes also act as an endocrine organ that releases soluble growth factors to regulate the physiological functions of distant organs such as the kidney ${ }^{32}$ for the maintenance of phosphate and vitamin D equilibrium. ${ }^{33}$

\section{BM MSCs}

MSCs are multifunctional non-HPCs. BM-derived MSCs (BMSCs) are a crucial MSC subgroup for osteogenesis and chondrogenesis. ${ }^{34}$ Due to their potent capacity for differentiation, BMSCs develop into cells such as BM stromal cells, skeletal myocytes, and osteoblasts. $^{35-37}$ Recently, BMSCs have been shown to display immunoregulatory properties. ${ }^{38,39}$ The BM microenvironment is potentially conducive to the development of T cells in the absence of the thymus. ${ }^{40,41}$ However, prior studies have indicated that BMSCs can inhibit the proliferation of mature $T$ cells and natural killer cells. ${ }^{42,43}$

Regulatory factors in the premetastatic niche

Compelling preclinical data have indicated that even before tumor cell migration, primary tumors can release soluble molecules into the circulation and prepare the soil for disseminating tumor cells. Exosomes are small vesicles of $\sim 100 \mathrm{~nm}$ in diameter that are released by cells. ${ }^{44}$ Exosomes secreted by cancer cells have recently been found to express integrins, a group of membrane receptors that allow the targeted movement of exosomes toward distant organs. ${ }^{45}$ For example, exosomes expressing integrin av $\beta 5$ preferentially move to the liver, while those expressing a6 $\beta 4$ target the lungs. ${ }^{45}$ The secreted exosomes are then internalized by the host organ cells, as a6 $\beta 4$-expressing exosomes colocalize with S100A4-positive fibroblasts in the lung and integrin av $\beta 5$ expressing exosomes colocalize with S100P-positive Kupffer cells in the liver. ${ }^{45}$ S100A4 and S100P belong to the S100 family, a group of acidic $\mathrm{Ca}^{2+}$-binding proteins that interact with various intracellular effector proteins and mediate downstream protein phosphorylation and cytoskeleton dynamics. ${ }^{46,47}$ The expression of S100A8/A9 is substantially elevated in human breast cancer cells, resulting in a migratory phenotype in cancer cells. ${ }^{48}$

The best-characterized function of lysyl oxidase (LOX) is extracellular matrix (ECM) remodeling, which by strengthening the crosslinking of collagen and elastin, thereby improving the structural integrity of the ECM. ${ }^{49}$ LOX expression can be induced under hypoxia, which is frequently observed in almost all solid tumors, and LOX can thus be used as a biomarker for premalignant changes during tumorigenesis. ${ }^{50}$ Moreover, LOX can prepare the premetastatic niche by activating bone resorption. ${ }^{51,52}$ Bone homeostasis is partly regulated by LOX activity, either directly through an RANKL-independent pathway BM stromal cells such as osteoblasts and osteoclasts ${ }^{52}$ or indirectly through RANKL-dependent mechanisms. ${ }^{53}$ In these ways, LOX disrupts bone homeostasis and facilitates premetastatic lesion formation. The elevated collagen fiber reticulation, ${ }^{54}$ which facilitates the anchorage and colonization of neoplasms in metastatic sites, ${ }^{51,54}$ is probably the cause of the protumoral effects of LOX. A recent investigation indicated that LOX silencing in primary tumors or antagonism of tumor-secreted LOX can prevent the formation of focal premetastatic lesions and the subsequent metastatic burden in bones. ${ }^{55}$ Prior studies have also found the existence of exosomes secreted by bone cells in the bone microenvironment. ${ }^{56-58}$ Exosomes can either be derived from osteoclasts to regulate osteoclastogenesis ${ }^{59}$ or released from osteoblasts to stimulate RANK signaling in osteoclast precursors, ultimately inducing osteoclast formation. ${ }^{60}$ One such example is exosomal-derived osteoclastic miR-214-3p, which is significantly correlated with bone formation in elderly female individuals with bone fractures. ${ }^{61}$

The hypoxic bone microenvironment could promote cancer cell metastasis and growth. A key mediator of hypoxic signaling is hypoxia-inducible factor-1 (HIF-1), which initiates the transcription of hypoxia-response-related genes. ${ }^{62}$ Many of these genes are prometastatic and are essential for angiogenesis, tumor cell apoptosis, and growth factor/cytokine activities. ${ }^{63}$ Tumor cells that can survive in the hypoxic bone microenvironment then colonize and thrive in bones, leading to a vicious cycle of bone metastases. HIF-1a interacts with several growth factors and cytokines, such as VEGF, insulin-like growth factors (IGFs), fibroblast growth factors (FGFs), and epidermal growth factor; the expression of these molecules on cancer cells can further enhance cancer cell proliferation and metastasis.

Extracellular $\mathrm{pH}$ in bones is associated with osteoblast and osteoclast function and with bone acidification leading to enhanced osteoclast resorption. ${ }^{64}$ Metastatic tumor cells in localized bone regions produce lactic acid, resulting in acidosis of the bone microenvironment. ${ }^{64}$ Tumor acidosis, in turn, increases the secretion of proteins that degrade the ECM and thus facilitate metastases, such as cathepsin B and matrix metallopeptidases (MMPs). ${ }^{65}$

\section{OSTEOLYTIC AND OSTEOBLASTIC BONE METASTASIS}

The two major categories of bone metastases are osteolytic and osteoblastic, based on which type of cells exhibit the predominant activities, ${ }^{66}$ and the impaired balance between bone formation and resorption is frequently observed in both types of metastasis. Despite the excess occurrence of bone resorption and formation, growing evidence has suggested the coexistence of osteolytic and 


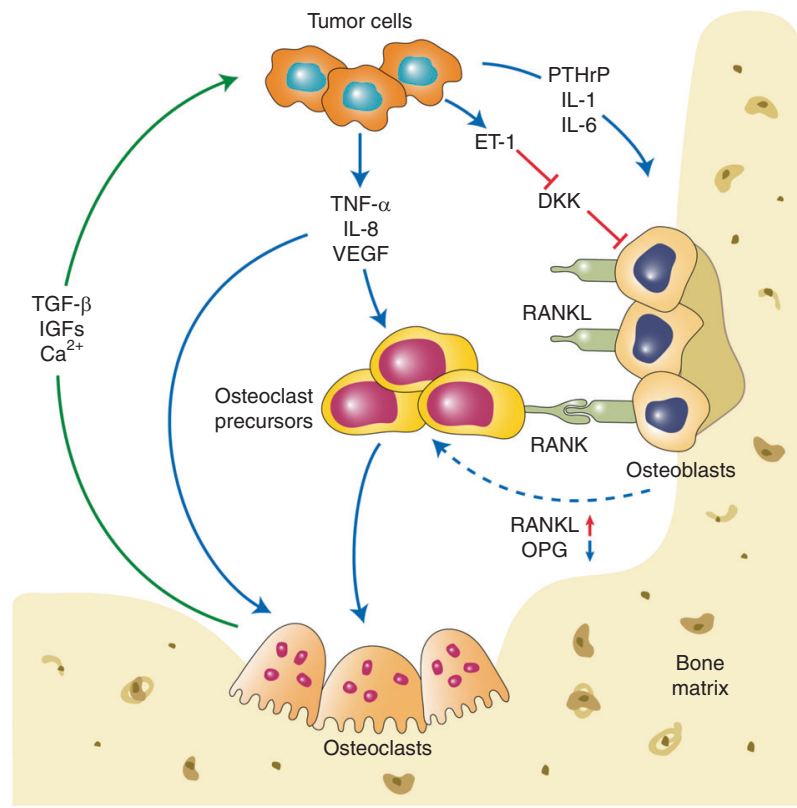

Fig. 1 The development of osteoclastic and osteoblastic bone metastases. Tumor cells interact with both osteoclasts and osteoblasts in the bone microenvironment, which leads to a local increase in tumor-derived factors to promote osteoclastogenesis and osteoblastogenesis. Mature osteoclasts, in turn, release survival factors, such as insulin-like growth factor 1 (IGF-1) and transforming growth factor beta (TGF- $\beta$ ), which promote the survival and proliferation of tumor cells

osteoblastic metastases, leading to mixed-type bone metastases. ${ }^{67}$ Based on the distinct cytokine profile detected, lung cancerderived bone metastases are preponderantly osteolytic, ${ }^{68}$ whereas prostate cancer shows preferential osteoblastic bone metastases. ${ }^{69}$ The development of osteoclastic and osteoblastic bone metastases is shown in Fig. 1.

Osteolytic bone metastasis

One prerequisite for the occurrence of osteolytic bone metastases is osteoclast activation. Osteoclasts are multinucleated cells that differentiate from their mononuclear macrophage/monocytelineage hematopoietic precursors and are involved in regulating intracellular calcium and inorganic phosphate levels. In the BM, multiple osteoclastogenic factors induce the differentiation of mononuclear macrophage/monocyte-lineage hematopoietic precursors into osteoclast precursors, which enter the bloodstream and localize to the remodeling sites of the bone. ${ }^{70}$ The differentiation of osteoclast precursors is initiated after exposure to the two main regulatory factors, macrophage colonystimulating factor and RANKL. RANKL, produced by osteoblasts, binds to its receptor RANK on the osteoclast precursor surface, which stimulates downstream signaling molecules, including mitogen-activated protein kinases (MAPKs) and phosphatidylinositol 3-kinase (PI3K)/Akt, and promotes the maturation of osteoclast precursors into functional osteoclasts. ${ }^{71}$ In addition to RANKL, osteoprotegerin (OPG), a decoy receptor that is produced by osteoblasts, eliminates RANKL and thus inhibits the RANK-RANKL signaling pathway. Therefore, the activation of osteoclasts is attributed to the delicate balance between RANKL and OPG. ${ }^{72,73}$

RANK/RANKL. RANK is a surface receptor of the tumor necrosis factor (TNF) family. ${ }^{74}$ This receptor is crucial for the formation, activation, and function of osteoclasts and also regulates calcium metabolism. ${ }^{75}$ Although RANK is considered to be primarily expressed on osteoclasts and their progenitors, recent studies have also detected its expression on tumor cells, indicating the potential participation of RANK in tumor metastasis. ${ }^{76,77}$ RANKL is a polypeptide that belongs to type II transmembrane proteins. ${ }^{78}$ RANKL, the ligand of RANK, can be expressed on the surface of osteoblasts and bone stromal cells and exists within the bone microenvironment in a soluble form. Recent investigations have also detected high expression of RANKL in osteocytes, suggesting an important role in bone remodeling. ${ }^{28,29}$ Moreover, RANKL has been found on both $T$ and $B$ lymphocytes. However, this molecule is not involved in bone remodeling under normal conditions. ${ }^{28}$ Several osteotropic factors, including parathyroid hormone (PTH), vitamin D3, TNF-a, Wht Family Member 5A, and IL-6, can stimulate RANKL expression, thus promoting osteoclastogenesis. ${ }^{79,80}$ In osteoclast precursor cells, RANKL enhances the production of mature osteoclasts through stimulation of M-CSF at low levels. ${ }^{81,82}$

RANK/RANKL signaling involves many transcription factors. The recruitment of TNF receptor-associated factors (TRAFs) is crucial for RANK/RANKL-mediated osteoclastogenesis, which activates various transcription factors, such as nuclear factor kappa beta and AP-1, and prevents the apoptosis of mature osteoclasts. ${ }^{83,84}$ RANKL also induces the phosphorylation of another transcription factor, microphthalmia transcription factor (MITF), and activates downstream MAPK. ${ }^{85}$ The stimulated transcription factor complex has a functional role in the expression of osteoclast-specific genes. The cytoplasmic domain of RANK recruits the adapter proteins Gab2 and PLCY2 and thus activates calcium signaling in osteoclastogenesis. ${ }^{86}$ PLC $\gamma 2$ then acts synergistically with costimulatory signals to activate NFATc1, a transcription factor regulated by calcium signaling. ${ }^{87,88}$ Furthermore, NFATc1 participates in the transcription of vacuolar ATPase and dendritic cellspecific transmembrane protein, which are closely related to the multinucleation of osteoclasts. ${ }^{8-91}$

In a breast cancer model, RANKL exerts its promigratory effect on cancer cells and thus promotes their metastasis to bone. ${ }^{92}$ Although breast cancer cells do not produce RANKL, they produce parathyroid hormone-related protein (PTHrP), which stimulates RANKL production in bone cells. ${ }^{93-95}$ PTHrP regulates the activation of osteoclasts as a specific mediator of osteolysis in breast cancer metastases. ${ }^{93,96}$ The expression of PTH-rP was significantly higher in breast cancer cells that metastasize to the bone than in those in nonbone soft tissues. ${ }^{97-99}$ Moreover, monoclonal antibodies (mAb) that target PTH-rP potently inhibited the progression of bone metastases. ${ }^{100}$ Hence, PTH-rP can promote bone metastases by activating the bone resorption activity of osteoclasts.

OPG. Conceptually, the balance between RANKL and OPG activities primarily determines the level of osteoclastogenesis, with a relatively higher OPG level leading to decreased bone resorption. ${ }^{101,102}$ OPG is a member of the small integrin-binding ligand $\mathrm{N}$-linked glycoprotein family and is a soluble receptor specific for RANKL. ${ }^{103}$ In this way, OPG competes with RANK for RANKL and thus hinders RANKL-RANK communication on the osteoclast cell membrane and disrupts osteoclastogenesis and subsequent bone resorption. ${ }^{104}$ However, some ECM components within bone microenvironments, such as glycosaminoglycans, may inhibit the RANKL-OPG interaction. ${ }^{105,106}$

In prostate cancers, the overexpression of OPG could inhibit the development of bone metastatic tumor cells, with no impact on the proliferation of tumor cells. ${ }^{107}$ Researchers have hypothesized that the essential role of osteolysis in tumor-bone metastases is to release growth factors from bones and to maintain the space needed for tumor growth in bone. In this indirect manner, OPG prevents bone lysis and thus reduces metastatic bone lesions. Previous reports have emphasized that the OPG produced by BM stromal cells was associated with the survival capacity of malignant prostate cells. ${ }^{108}$ As described earlier, OPG can also 
be produced by cancer cells and protects cancer cells from TNFrelated apoptosis-inducing ligand-induced apoptosis in a prostate cancer model. ${ }^{109}$ However, a recent study found that the serum level of OPG was increased in patients with prostate cancer bone metastasis compared with nonmetastatic patients. ${ }^{110}$ These contradictory results indicate the need for further studies on the role of serum OPG level as a bone metastatic marker of prostate cancers.

Calcium-sensing receptor (CaSR). Extracellular calcium released from the bone matrix plays an active role in the vicious cycle of cancer bone metastasis. Under physiological conditions, the calcium balance is delicately maintained within a physiologic range in the bone microenvironment. The extracellular calcium of cancer cells is recognized through the CaSR or the P2X receptor, which manipulates calcium influx and efflux through ion channels or transporters. Therefore, once cancer cells reach bones, exposure to high calcium concentrations in the microenvironment, in turn, activates the CaSR. Although some evidence indicates that CaSR plays a tumor-suppressive role in gastric and colon cancers, ${ }^{111,112}$ this receptor has also been shown to promote bone metastasis of some other cancer types, such as renal cell carcinoma (RCC), as CaSR is widely detected in both normal and malignant renal tissues. ${ }^{113}$ In a clinical study, higher expression of CaSR was observed in RCC patients with bone metastases than in primary cancer patients 5 years after surgery. ${ }^{114}$ Due to the osteolytic activities in RCC bone metastases, the high serum calcium concentrations may potentially increase the activities of CaSRexpressing tumor cells. ${ }^{115}$ A recent study found that CaSR overexpression increased the adhesion, migration, and proliferation of RCC cells in a calcium-dependent manner, indicating that cellular calcium might enhance the metastatic behavior of RCC via CaSR. ${ }^{116}$ Similar findings were reported in breast cancer cells in which the overexpression of CaSR was correlated with an increase in osteolytic potential. ${ }^{117}$

TNF-a. TNF- $a$, a proinflammatory cytokine, is frequently observed in the tumor microenvironment and is mainly produced by tumorassociated macrophages and tumor cells. ${ }^{118-120}$ TNF-a was reported to accelerate tumor cell apoptosis at a high dose. ${ }^{121}$ However, when released into the tumor microenvironment, TNF-a also promotes cancer metastases at a low dose. ${ }^{122}$ The proinflammatory cytokine TNF- $a$ is one of the strongest inducers of bone resorption. ${ }^{123}$ This molecule can stimulate the expression of RANKL and M-CSF in stromal cells, osteoblasts, and activated $\mathrm{T}$ cells ${ }^{124-127}$ and directly promote the formation of $\mathrm{TRAP}^{+}$ multinucleated osteoclasts in the presence of M-CSF and the absence of RANKL by activating NF-KB and AP-1 signaling. ${ }^{128-131}$ Moreover, a recent investigation reported the correlation between RANKL and TNF- $a$ in osteoclastogenesis. ${ }^{132}$ TNF- $a$ induces osteoclast differentiation from TRAF6 ${ }^{-1-}$ osteoclast precursors through the RANKL-mediated degradation of TRAF3, suggesting that RANKL could enhance TNF-a-induced osteoclastogenesis in a TRAF6-independent manner. ${ }^{132}$ In RA patients, TNF-a upregulates the IL-34 level via the NF-KB and JNK signaling pathways, 133 and TNF- $a$ inhibitors, such as infliximab, adalimumab, certolizumab, and golimumab, have all shown clinical success. ${ }^{134}$

Interleukins (ILs). IL-1, either directly or indirectly, acts on the differentiation of osteoclasts depending on the levels of other growth factors in the bone microenvironment. ${ }^{135,136}$ For example, IL-1a has been reported to directly induce osteoclast differentiation through MITF in BM macrophages in an RANKL-independent mechanism. ${ }^{137}$ However, the activation of osteoclastic markers, such as TRAP, cathepsin K, and MMP-9, by IL-1a can also be associated with RANKL levels. ${ }^{138}$ IL-1 $\beta$, a proinflammatory cytokine, can potently stimulate osteoclast differentiation and subsequent bone resorption. ${ }^{139}$ Likewise, IL-1 $\beta$ either indirectly stimulates TNF-a-induced osteoclastogenesis by inducing RANKL expression or directly promotes p38 MAPK-regulated osteoclastogenesis in the presence of sufficient RANKL. ${ }^{140}$ Treatment strategies targeting IL-1, such as IL-1 receptor inhibitors (e.g., anakinra) and IL-1 antagonists (e.g., rilonacept and canakinumab), are now in clinical use for RA patients. ${ }^{141}$

The IL- 6 cytokine family members share a common subunit, gp130, in their signaling receptor complex. ${ }^{142}$ IL-6 promotes osteoclastogenesis via interaction with the IL-6 receptor (IL-6R), which induces RANKL expression in osteoblasts and stromal cells. ${ }^{143}$ Interestingly, OPG treatment failed to prevent osteoclastogenesis induced by IL- 6 in the presence of M-CSF, which could be inhibited by a gp130 antibody. ${ }^{144}$ Likewise, in an animal model, anti-human IL-6R antibodies could also prevent bone metastases. ${ }^{145}$ Thus, IL-6 may promote osteoclastogenesis in an RANKL-independent manner. ${ }^{146}$ One study, however, has reported the suppressive function of IL-6 in osteoclast differentiation; IL- 6 inhibited RANK-mediated NF-KB and JNK activation. ${ }^{143}$ This result was supported by a recent study showing that the IL- 6 and IL-6R interaction could differentially manipulate RANKLinduced osteoclastogenesis via the NF-KB, ERK, and JNK signaling pathways. ${ }^{147}$ In the presence of low-level RANKL, IL-6/IL-6R enhanced osteoclastogenesis, which was significantly suppressed by high-level RANKL. Thus, IL-6 can act either as an osteoclastogenic factor or bone protector, depending on the level of RANKL in the bone microenvironment. Oncostatin M (OSM), a member of the IL-6 family, exhibits multiple effects in physiological processes, including hematopoiesis, neurogenesis, and bone homeostasis. ${ }^{148}$ OSM was shown to promote epithelial to mesenchymal transition (EMT) ${ }^{149}$ and tumor cell invasion, ${ }^{150,151}$ as well as upregulate proteases to degrade the local ECM in breast cancer. ${ }^{151,152}$ In an in vitro experiment, breast cancer cell lines cocultured with OSM showed increases in osteoclastogenesis, which could be reversed by treatment with amphiregulin, an antibody targeting a previously uncharacterized OSM-regulated bone metastatic factor. ${ }^{153}$

By increasing the release of RANKL and TNF-a in T cells, IL-7 has previously been identified as an indirect stimulator of osteoclast formation. ${ }^{154-157}$ TNF-a, in turn, stimulates IL-7 production, which promotes the expansion of IL-17-producing T helper 17 (Th17) cells. ${ }^{126}$ The Th17 cytokine IL-17 is an RANKL inducer known to disturb the RANKL/OPG balance and ultimately lead to bone resorption. ${ }^{158}$ A recent investigation, however, indicated that IL-7 could directly induce osteoclastogenesis via STAT5 signaling, which was independent of RANKL. ${ }^{159}$ Other pathways were then identified by the neutralization of IL-17A, which blocked C-X-C chemokine receptor type 4 (CXCR4)/SDF1 signaling in metastatic microenvironments and substantially decreased bone metastases. ${ }^{160}$ However, the inhibitory effect of IL-17 on osteoclastogenesis, which mainly involves the induction of granulocyte-macrophage colony-stimulating factor (GM-CSF) in osteoblasts, has been observed. ${ }^{161}$ GM-CSF is secreted by cells, including activated T cells, fibroblasts, and macrophages, and then stimulates osteoclastogenesis via Ras/ERK signaling. ${ }^{162,163}$ GM-CSF was shown to increase the number of osteoclast precursors within the bone microenvironment, ${ }^{164}$ which is contradictory to another study suggesting that the expression of TNF-a-induced GM-CSF suppresses hematopoietic precursors of osteoclasts. ${ }^{165}$ Therefore, the role of GM-CSF in osteoclastogenesis remains unclear.

IL-11 has long been identified as a functionally pleiotropic member of the IL-6 cytokine family due to its capacity to stimulate IL-6-dependent cell proliferation. ${ }^{166}$ This molecule is initially produced in a BM-derived stromal cell line and can be released by mature osteoblasts to enhance osteoclastogenesis. ${ }^{167}$ An early study demonstrated that various osteotropic factors, including IL-1, TNFa, PGE2, PTH, and 1 alpha, 25dihydroxy vitamin D3 [1 alpha, $\left.25(\mathrm{OH})_{2} \mathrm{D} 3\right]$, could promote the 
production of IL- 11 by osteoblasts, whereas IL- 6 , IL-4, and TGF- $\beta$ could not. ${ }^{168,169}$ In cocultures of both osteoblasts and BM cells, IL-11 induced the formation of osteoclast-like multinucleated cells in a dose-dependent manner, but this process was strongly inhibited by anti-IL-11 antibodies. ${ }^{170} \mathrm{~A}$ recent clinical study found that the serum levels and mRNA expression of IL-11 in breast cancer patients were significantly elevated in the metastatic group compared with the nonmetastatic group, suggesting that IL-11 has predictive value in breast cancer bone metastasis. ${ }^{171}$

IL-8 is another potential stimulator of osteoclastogenesis and bone destruction in bone metastases. ${ }^{172} \mathrm{IL}-8$ may bind to the IL- 8 receptor (IL-8R) on the osteoclast surface independent of RANK-RANKL signaling, ${ }^{173}$ and IL-8 antibodies or IL-8R inhibitors significantly suppressed osteoclast differentiation in vitro. ${ }^{174} \mathrm{~A}$ recent study suggested that the serum level of IL-8 was elevated in patients with anti-citrullinated protein antibody (ACPA)positive RA and that ACPA-induced osteoclastogenesis can be inhibited by IL- 8 neutralizing antibodies. ${ }^{175}$

\section{Osteoblastic bone metastasis}

Despite recent research efforts on osteoclastic bone metastases, little is known about this condition, which mainly occurs in advanced prostate cancers and less frequently occurs in breast cancers. Osteoblasts are stimulated by metastatic tumor cellderived factors, including FGFs, urokinase-type plasminogen activator (UPA), endothelin-1 (ET-1), prostate-specific antigen (PSA), IGFs, bone morphogenic proteins (BMPs), and VEGF. ${ }^{176-180}$ ET-1 plays a vital role in the osteoblastic response to cancer bone metastasis. ${ }^{181}$ The binding of ET-1 to the endothelin A receptor (ETAR) downregulates the autocrine production of a Wnt antagonist, Dickkopf-1 (Dkk-1). ${ }^{182,183}$ The subsequent Wnt pathway activation is crucial for the differentiation and function of osteoblasts. Moreover, a previous study reported that the inverse correlation between the level of Dkk-1 and osteoblastogenesis is independent of osteoclastogenesis. ${ }^{184}$

ET-1. ET-1, acknowledged as a vasoactive peptide, is actively involved in the formation of new bone in the context of osteoblastic bone metastasis. ${ }^{185,186}$ In a mouse tumor model, the osteoblastic metastasis of breast cancers was closely associated with the secretion of ET-1, the activity of which relied on its binding to ETAR. ${ }^{181}$ The study also demonstrated that ETAR blockade strongly suppressed osteoblastic bone metastasis and reduced the tumor burden in bone, suggesting the potential value of ETAR inhibitors for bone metastatic cancer patients. ${ }^{181}$ However, no precise molecular mechanisms for ET-1-regulated bone metastases have been established. Previous research has indicated that ET-1 can suppress osteoblast apoptosis by stimulating the calcineurin/NFAT pathway. ${ }^{187}$ This process may also involve E-cadherin augmentation, which correlates with tumor cell adhesion, as well as upregulated Runx2 activity and SPARC expression, which is related to osteomimicry. ${ }^{188,189}$ The inductive effect of ET-1 on IL-18 expression has been identified in osteoblasts at the gene promoter/transcriptional level through a p38 MAPK-dependent pathway. ${ }^{190}$ IL-18, as discussed above, acts as a regulator of osteoblast proliferation. A recent study also evaluated the impact of ETS proto-oncogene 1 (ETS-1) and HIFs on ET-1 signaling and found that the balance between ETS-1 and HIF might affect downstream signals represented by ET-1. ${ }^{191}$

DKK-1. As discussed earlier in the review, bone metastases usually have a mix of osteolytic and osteoblastic metastases. Accumulating evidence has suggested that osteolysis is the first step, even in the osteoblastic metastasis setting. In prostate cancer bone metastasis, DKK-1 acts as a molecular switch that converts osteolytic metastasis to osteoblastic metastasis. ${ }^{192}$ DKK-1 also enhances the bone metastasis of breast cancers through the regulation of canonical WNT pathways in osteoblasts. However, targeting canonical WNT alone may fail to prevent cancer metastases, whereas combinational inhibition of JNK and TGF- $\beta$ signaling could effectively treat cancer metastases to the lung and bone. ${ }^{193}$ Cancer cells themselves can also secrete DKK-1 and regulate DKK-1 levels in the local microenvironment independently of ET-1. For example, PC3, a prostate cancer cell line, could produce DKK-1 and was converted from an osteolytic to an osteoblastic phenotype when transfected with Dkk-1 siRNA. ${ }^{184}$ In a clinical setting, the serum levels of DKK- 1 were robustly elevated in breast cancer patients with bone metastases compared with healthy controls or nonmetastatic patients. ${ }^{194}$ Another inhibitor of WNT signaling is SOST, the functional loss of which may lead to multiple bone disorders due to dysregulation of bone remodeling. ${ }^{195,196}$ Sclerostin, known as the protein product of the SOST gene, can inhibit canonical WNT signaling ${ }^{197,198}$ and thus promote bone formation. ${ }^{199}$

Other factors regulating osteoblastic bone metastasis. The role of PTHrP in osteoblastic metastases, particularly in prostate cancers, has long been disputed. ${ }^{200}$ The expression of PTHrP correlates with increased malignancy and incidence of skeletal metastasis in multiple cancers, including prostate cancers. ${ }^{201,202}$ Tumor-derived PTHrP not only plays an important role in the bone remodeling process but also directly facilitates the proliferation, adhesion, and survival of tumor cells. ${ }^{203-205}$ PTHrP was shown to potently stimulate osteoclastogenesis by increasing the production of RANKL by osteoblasts. ${ }^{206}$ However, PTHrP also facilitates osteoblastic alterations. ${ }^{207}$ PSA, a serine proteinase, can cleave PTHrP into fragments at residue $23^{208}$ impairing PTH/PTHrP-mediated activation of its receptor. ${ }^{209}$ Given the structural similarity between PTHrP-1-16 and ET-1 in the N-terminus, the inactive fragment PTHrP-1-16 can bind to and thus activate ETAR. ${ }^{210}$ In addition to its cleavage of PTHrP, PSA may stimulate osteoblasts by preventing IGF from its binding protein and transforming latent TGF- $\beta$ into its active form. ${ }^{211,212}$ In vivo studies are needed to demonstrate PSA-mediated bone metastasis, as most of the evidence thus far is based on in vitro studies. ${ }^{213}$ Prostate cancer cells also secrete the paracrine factor BMP4, an activator of osteoblast differentiation. ${ }^{214} \mathrm{~A}$ recent study suggested that BMP4 might potentially mediate the endothelial-to-osteoblast (EC-toOSB) conversion of endothelial cells into osteoblasts (28586644), which was consistent with previous reports that treatment with a BMP receptor inhibitor in mice with prostate cancer significantly prevented tumor-induced bone formation (21670081). Furthermore, prostate cancer cells produce FGF-9, which promoted the osteoblastic phenotype of MDA PCa-118 xenografts. ${ }^{215}$

\section{THE MULTISTEP PROCESS OF BONE METASTASES}

Bone metastasis does not occur randomly. This process is a wellorganized procedure that involves a vicious cycle between the tumor and bone, where one promotes the other, disrupting the bone matrix and leading to bone metastasis. ${ }^{216,217}$ The general bone metastatic process can be divided into cancer cell escape and dissemination, adhesion and invasion to the bone, and metastasis in bone. The general multistep process of bone metastasis and its regulating factors are presented in Fig. 2 and Table 1.

\section{Cancer cell escape and dissemination}

The ability of tumor cells to escape their local microenvironment and degrade ECM proteins is an integral part of the malignancy of cancers. To intravasate into the bloodstream and colonize the metastatic site, tumor cells must pass through the basement membrane and the ECM. MMPs are a superfamily of multiple zincdependent proteinases that degrade ECM proteins. ${ }^{218}$ High MMP levels have been observed in various malignancies, including 




Fig. 2 The general multistep process of bone metastasis and its correlated regulatory factors

prostate, bladder, lung, and breast cancers, as well as head and neck squamous cell carcinomas, ${ }^{219-222}$ and are correlated with poor clinical outcome. 223,224

The MMP family is closely correlated with angiogenesis. Both in vitro and in vivo investigations have reported the antiangiogenic effect of MMP inhibitors. ${ }^{225-227}$ The angiogenic response was shown to be significantly reduced in MMP-deficient mice. ${ }^{228,229}$ Of all the MMP members, MMP-2 is the best-studied protein due to its function in angiogenesis. The addition of exogenous pro-MMP-2 to endothelial cell culture could lead to morphologic changes that indicate angiogenesis. ${ }^{230}$ Furthermore, MMP-2 acts synergistically with adhesion molecules (e.g., Ecadherin). ${ }^{231}$ High expression of both MMP-2 and MMP-9 (an MMP family member closely related to MMP-2) was linked to a poor prognosis in breast cancer. ${ }^{224}$ In support of this hypothesis, MMP-2 positivity indicated an increase in the risk of death in the first 10-year follow-up. ${ }^{232}$ Furthermore, MMP-2 was substantially elevated in patients with HER2/neu gene-amplified tumors, known as an aggressive tumor phenotype. A previous investigation evaluating the association between MMP-2 and clinicopathological parameters found that MMP-2 was an indicator of more invasive phenotypes and was related to lymph node metastasis. ${ }^{233}$ MMP-2 also induces angiogenesis through the regulation of VEGF and the cleavage of ECM molecules (e.g., type IV collagen) ${ }^{234,235}$ and therefore facilitates angiogenesis in the tumor microenvironment. $^{236}$ However, previous studies have found that MMP-2 promotes the release of bioactive fragments of ECM, such as endostatin, ${ }^{237}$ restin, ${ }^{238}$ and arrestin, ${ }^{239}$ which inhibits angiogenesis. This inhibitory effect is related to the dormancy of breast cancer, where MMP-2 induces disseminated breast tumor cells to enter dormancy by promoting the expression of the dormancy promoter TGF- $\beta 2$ in the $\mathrm{BM}^{240}$ A recent report found that thrombospondin-2 could promote the migration of prostate cancer cells by enhancing MMP-2 expression. ${ }^{241}$

Osteolytic bone metastasis was significantly reduced in an MMP7-deficient prostate cancer model, which had low levels of osteolysis due to defects in RANKL processing and osteoclast activation. ${ }^{242}$ MMP-7, producing a soluble form of RANKL from membrane-bound RANKL, promotes osteolytic bone metastases in prostate cancer. ${ }^{242}$ In prostate cancers, tumor growth in the bone microenvironment can be stimulated by osteoclast-derived MMP-9, which enhances angiogenesis without altering the osteolytic or osteogenic properties of tumors. ${ }^{243}$ However, BMP-6, a member of the TGF- $\beta$ superfamily, suppresses the paracrine secretion of MMP9 in breast cancer cells via MAPK/p38/AP-1 signaling. ${ }^{244}$ MMP-13 overexpression was first detected in breast carcinomas and was potentially induced by IL- $1 a$ and IL-1 $\beta .^{245,246}$ In squamous cell carcinomas, MMP-13 is predominantly expressed on cancer cells and the stromal fibroblasts surrounding the cancer cells. In addition, MMP-13 is strongly indicative of the invasive and metastatic capacity of tumors. ${ }^{247,248}$ The specific role of MMP-13 has not yet been elucidated in breast cancer. A recent investigation revealed that the upregulation of MMP-13 in the tumor-stromal interaction, especially at the tumor-bone interface, is crucial to tumor-induced osteolysis, suggesting the potential value of MMP13 in the treatment of breast cancers with bone metastasis. ${ }^{249}$

Cancer cell adhesion and invasion

Among all the chemokines, SDF1a (also known as CXCL12) is particularly involved in bone metastasis ${ }^{250}$ and is often expressed in common metastatic sites such as BM. CXCR4 and CXCR7 represent two cognate receptors for CXCL12. ${ }^{251-253}$ Both CXCR7 and CXCL12 are highly expressed on certain cancer cells. ${ }^{254,255}$ CXCL12 can also be detected in normal tissues such as blood vascular endothelial cells, ${ }^{25,256}$ and fibroblasts are probably a major source of CXCL12 secretion in tumor tissue. ${ }^{257,258}$ Initially shown to facilitate the mobilization of hematopoietic stem cells and create a microenvironment for cancer stem cells, ${ }^{259}$ CXCL12/ CXCR4 pathway signaling also plays an important role in cancer cell proliferation and angiogenesis. ${ }^{259,260}$

The inhibition of the CXCL12/CXCR4 interaction with CXCR4 mAb or CXCR4 blocking peptides prevents the migration of bone metastases of prostate cancer cells ${ }^{261}$ and reduces the in vivo metastatic load. ${ }^{260}$ Experimental evidence suggests that the CXCL12/CXCR4 signaling axis participates in prostate cancer cell adhesion to BM endothelial cells. ${ }^{262-264}$ Consistent with this hypothesis, antagonists of av $\beta 3$, an adhesion-related integrin induced by CXCL12, significantly decreased the adhesion of 
Table 1. Regulating factors associated with the bone metastasis process

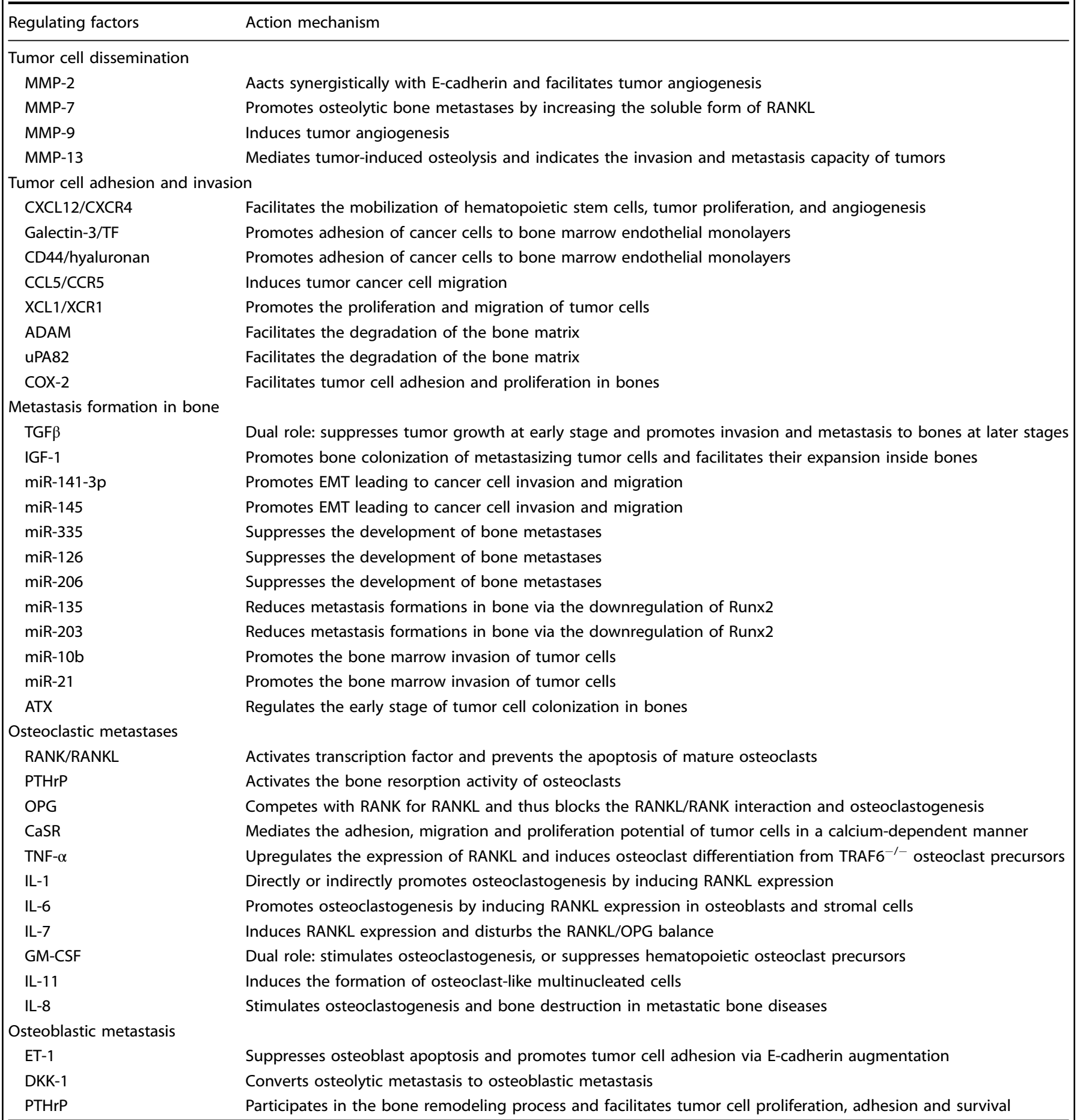

MMPs matrix metallopeptidases, CXCR4 C-X-C chemokine receptor type 4, TF Thomsen-Friedenreich, COX-2 cyclooxygenase-2, TGF- $\beta$ transforming growth factor beta, IGF insulin-like growth factor, miRNA microRNA, ATX autotaxin, RANL receptor activator of nuclear factor kappa-B ligand, PTHrP parathyroid hormone-related protein, OPG osteoprotegerin, CaSR calcium-sensing receptor, TNF tumor necrosis factor, GM-CSF granulocyte-macrophage colony-stimulating factor, ET-1 endothelin-1, Dkk-1 Dickkopf-1

prostate cancer cells to endothelial cells. ${ }^{265}$ CXCL12/CXCR4 is not the only signaling pathway involved in the adhesion of prostate cancer cells to endothelial cells but is instead part of a sequence of other interactions, such as those involving CD164. ${ }^{266}$

HER2/CXCR4/AKT signaling has been investigated in the bone metastasis of breast cancers. ${ }^{267}$ High expression of CXCR4 is found in breast cancer cells, promoting tumor cell homing and bone metastasis, with a highly osteolytic subclone observed in a breast cancer cell line. ${ }^{268}$ Addition of an anti-CXCR4 antibody or gene silencing of CXCR4 significantly decreased the migration of breast cancer cells to regional lymph nodes and the lung. ${ }^{269}$ Multiple preclinical studies have assessed the effectiveness of CXCR4 in 
blocking bone metastases in breast cancers. ${ }^{269,270}$ However, the CXCL12/CXCR4 axis can facilitate bone invasion processes by inducing MMP-9 and downregulating the expression of tissue inhibitor of metalloproteinases 2 in prostate cancer cells by this pathway. ${ }^{271,272}$ MMP family members are not only involved in cancer cell escape but also promote the extravasation of cancer cells from the ECM before proliferation in bones. ${ }^{265}$ Given that broad-spectrum MMP inhibitors fail to demonstrate clinical efficacy, more individualized targeting of proteinases may be a promising strategy to prevent bone metastases in cancer patients.

In addition to the CXCR4/CXCL12-induced CD164 and av $\beta 3$ integrins mentioned above, a vast majority of adhesion molecules have been discovered in the interaction of cancer cells with BM endothelium. These molecules include galectin-3/ Thomsen-Friedenreich antigen ${ }^{273,274}$ as well as CD44/hyaluronan, ${ }^{275}$ the inhibition of which impairs the adhesion of cancer cells to BM endothelial monolayers. Another member of the chemokine superfamily, CCL5, is produced by BMDCs and local stem cells in the bone microenvironment, and together with its receptor CCR5, CCL5 enhances cancer bone metastases. ${ }^{276,277} \mathrm{~A}$ recent report identified an increase in CCL5 secretion from bone stromal cells in the metastatic microenvironment, which induced prostate cancer cell migration involving androgen receptor signaling. ${ }^{278}$ The lymphotactin receptor (XCR1) is also a member of the chemokine receptor family, and its interaction with the ligand XCL1 substantially promotes the proliferation and migration of cancer cells. ${ }^{279-281}$ Other cancer cell-derived proteinases, such as $\mathrm{ADAM}^{282}$ and uPA $82,{ }^{271}$ are also implicated in the degradation of the bone matrix, promoting the effective invasion of cancer cells into bones. A recent study demonstrated the positive effect of cyclooxygenase-2 $(C O X-2)$ on cell adhesion and proliferation in bones. ${ }^{283}$ Human melanomas frequently overexpress the COX-2 gene, ${ }^{284}$ which exerts its regulatory effect on melanoma cell adhesion to proliferation in BMSCs in response to BMSC-derived VEGF. ${ }^{283}$

Metastasis formation in bone

In addition to the processes by which cancer cells escape from original sites and invade bones, another fundamental step toward bone metastasis is the maintenance of cell proliferation as well as the consequent formation of metastases. As discussed above, the proposed mechanism for bone metastasis is the disruption of normal bone remodeling, leading to imbalanced bone resorption and bone formation. For cancer cell survival and growth, multiple growth factors produced by osteoblasts are embedded within the bone matrix and released during osteoclastic bone resorption. ${ }^{285}$

TGF- $\beta$. TGF- $\beta$ participates in various normal physiological procedures, including immune responses and bone remodeling, ${ }^{286}$ and is also an important growth factor for osteoclastic bone resorption. Enhanced TGF- $\beta$ signaling was detected in both preclinical ${ }^{287-290}$ and clinical breast cancer models. ${ }^{288}$ The TGF- $\beta 1$ level was significantly elevated in the plasma of breast or prostate cancer patients with bone metastases. ${ }^{291}$ Smad-dependent TGF- $\beta$ signaling was also observed in samples of the bone metastatic sites of breast cancer patients. ${ }^{292}$ However, TGF- $\beta$ can play a paradoxical role in cancer, where it suppresses tumor growth at an early stage and promotes invasion and metastasis to bones at later stages. ${ }^{293}$ Various genes referred to as bone metastasis stimulators, including CXCR4, MMP-1, IL-11, JAG1, and PTHRP, were shown to be regulated by TGF- $\beta,{ }^{288,294,295}$ and anti-TGF- $\beta$ therapies showed strong efficacy in controlling cancer-related bone metastases in mice. ${ }^{289,296}$

IGF. The IGF family is essential for bone growth, ${ }^{297}$ as all skeletal cells express IGF-1 and its receptor IGF-1R to maintain physiological functions. ${ }^{297}$ Moreover, IGF-1 promotes bone colonization of metastasizing tumor cells and facilitates their expansion inside bones. One such example is breast cancer metastasis stimulated by bone-derived IGFs through the activation of AKT and NF-KB to increase the proliferation and survival of cancer cells. ${ }^{298}$ In addition to the survival of cancer cells in bone, IGFs participate in the homing process. In triple-negative breast cancers, cancerassociated fibroblasts release IGF-1, which primes cells to home to the IGF-1-rich bone microenvironment. ${ }^{299}$ In prostate cancer with bone metastases, IGF-1 causes resistance-related genetic alterations of cancer cells through its binding to IGF-R, which has been identified in several proliferative and antiapoptotic mechanisms. ${ }^{300}$ This protective effect of IGF-1 on prostate cancer cells can be antagonized by agents that downregulate both local and systemic IGF-1 production, which is used to improve symptoms among prostate cancer patients with bone metastases. ${ }^{301-303}$

MicroRNA (miRNA). To better adapt to the bone microenvironment, cancer cells undergo osteomimicry, which involves gene expression that is normally found on bone cells. The well-ordered expression of metastasis-related molecules during adaptation suggests that miRNAs are crucial regulators of osteomimicry. By binding to corresponding sequences in downstream target genes, miRNAs degrade and inhibit the translation of mRNAs. ${ }^{304}$ Accumulating evidence suggests that the aberrant expression of miRNAs indicates the invasive and metastatic phenotypes of tumor cells, ${ }^{305-307}$ and several miRNAs have been identified to mediate bone metastases, especially those of prostate cancer. $^{308-310}$ MiR-141-3p is one of the earliest studied miRNAs. Previous studies found that the dysregulation of miR-141-3p is involved in the metastatic behavior of cancer cells. ${ }^{311,312}$ The expression of miR-141-3p disrupts NF-KB signaling by targeting TRAF5 and TRAF6, and the silencing of miR-141-3p promotes EMT, leading to cancer cell invasion and migration. ${ }^{313}$ Likewise, the downregulation of miR-145 caused by loss of wild-type p53 could promote bone metastasis through enhanced EMT. ${ }^{314,315} \mathrm{~A}$ growing number of miRNAs, such as miR-133b and miR-19a-3p, which directly target the activity of TGF- $\beta$ signaling, have recently been shown to negatively regulate bone metastases of prostate cancers. ${ }^{316,317}$

Furthermore, the decreased expression of several miRNAs (e.g., miR-335, miR-126, and miR-206) was detected in human breast cancer cells metastasizing to the bone, and the restoration of their expression prevented bone metastatic progression. ${ }^{318}$ MiR-135 and miR-203 have been reported to downregulate the expression of Runx2 in breast cancer cells, thus reducing metastasis formation in bone. ${ }^{319}$ MiRNAs do not always exert negative effects on bone metastases, and some of them act as onco-miRNAs. The stimulation of miR-10b and miR-21, caused by the transcription factor Twist- 1 and lysophosphatidic acid, respectively, promoted the invasion of breast cancer cells in $\mathrm{BM}^{320}$

Autotaxin. Autotaxin (ATX or ENPP2) is a member of the nucleotide pyrophosphate-pyrophosphatase family. The expression of ATX in human primary breast tumor biopsies does not impact overall survival (OS), indicating that its expression at the primary tumor sites is not a prognostic indicator. ${ }^{321}$ However, a recent study showed that nontumoral ATX directs the early stage of tumor cell colonization in bones. ${ }^{322}$

\section{MANAGEMENT OF CANCER BONE METASTASES}

The optimal treatment of cancer bone metastases involves a multidisciplinary approach, including medical oncology, radiation oncology, and surgical oncology. Based on the basic biology of bone metastasis discussed above, concomitantly preventing new metastases and the growth of established metastases is theoretically an effective therapeutic strategy. ${ }^{323}$ The main treatment strategies for cancer bone metastasis are summarized in Table 2.

\section{Hormone therapies}

Endocrine therapies are considered a first-line treatment for hormone-responsive cancer patients. For many years, tamoxifen, a selective estrogen receptor modulator (SERM), has been regarded 
Table 2. The main treatment strategies for cancer bone metastasis

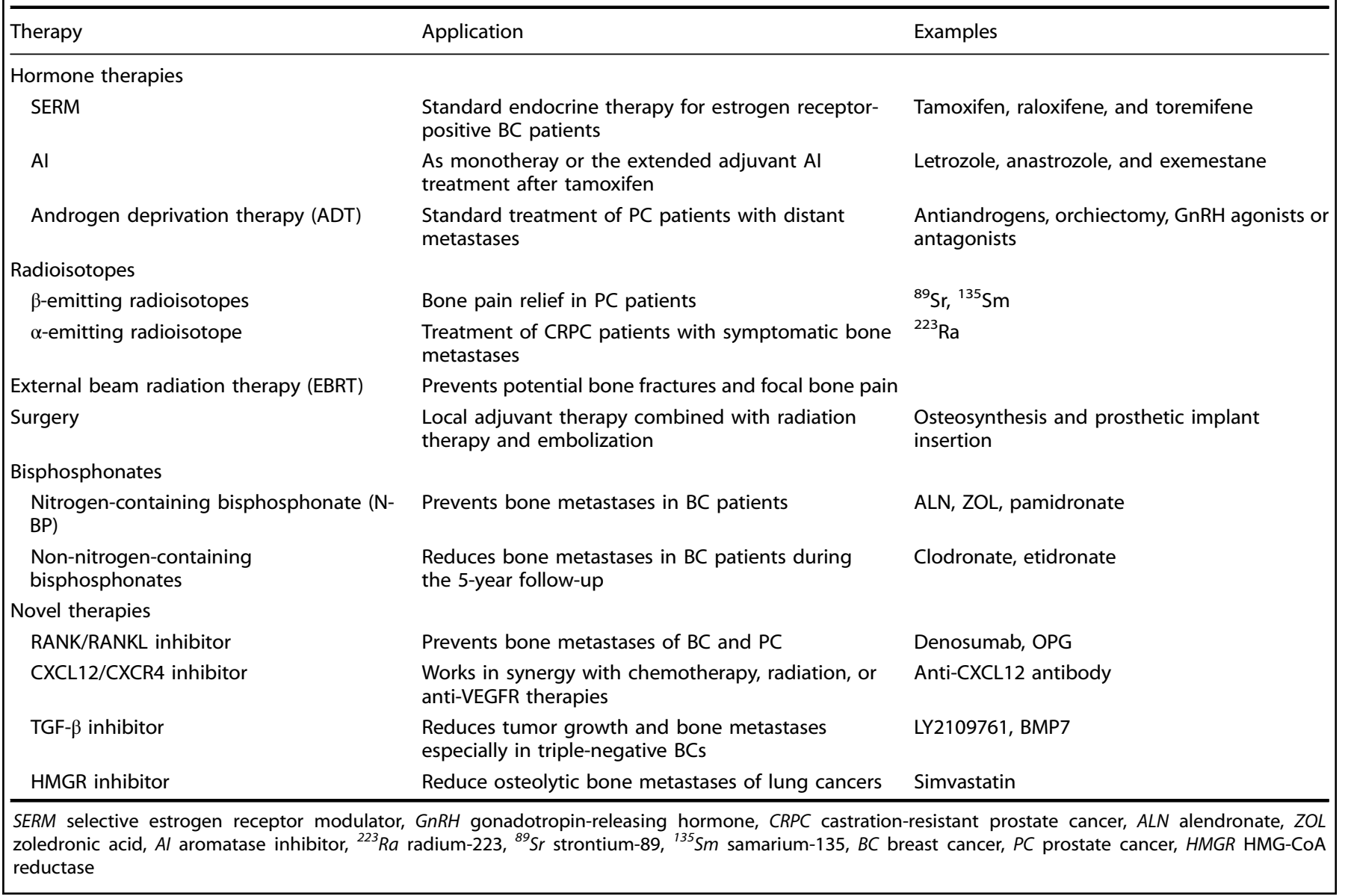

as the standard endocrine therapy for patients with estrogen receptor-positive breast cancer. Based on clinical research, postsurgical tamoxifen treatment decreases breast cancer mortality by $34 \% .{ }^{324}$ Other SERMs, including raloxifene and toremifene, have also been found to efficaciously block cell growth in patients with estrogen-responsive breast cancers. ${ }^{325-328}$ Aromatase is a key enzyme implicated in estrogen biosynthesis and converts androgens to estrogens. Recently, multiple large randomized trials have compared third-generation aromatase inhibitors (Als), such as anastrozole, exemestane, and letrozole, with tamoxifen and found that $\mathrm{Al}$ therapies are more efficacious and tolerable in patients with breast cancer. ${ }^{329-332}$ Thus, Als have now replaced SERMs in female cancer patients, especially postmenopausal women. ${ }^{333-336}$ Clinical treatment regimens include the upfront $\mathrm{Al}$ monotherapy, $^{329,337} 2-3$ years of tamoxifen prior to Al treatment, ${ }^{338-340}$ and extended adjuvant Al treatment. ${ }^{341,342}$ However, the Al-induced decrease in estrogen levels contributed to increased risks of bone resorption ${ }^{343}$ and fractures. $329,332,344$

Androgen deprivation therapy (ADT), a standard treatment for prostate cancer patients with distant metastases, ${ }^{345,346}$ can be achieved by antiandrogens, orchiectomy, and agonists or antagonists of gonadotropin-releasing hormone. ${ }^{347}$ The majority of ADT-treated patients experience symptomatic relief, metastasis regression, and decreased serum levels of PSAs. Similar to estrogen deprivation, ADT is also related to skeletal complications such as decreased bone mineral density and fracture risk. ${ }^{348-351}$ Abiraterone acetate is known to target CYP17A1, an essential enzyme for androgen synthesis, and substantially improved OS in prostate cancer patients with bone metastases. ${ }^{352,353}$ Similar results were obtained from another androgen receptor antagonist, enzalutamide, which is used as a first-line intervention for bone metastatic prostate cancer patients after castration and docetaxel treatment. ${ }^{354,355}$ However, most patients with prostate cancer eventually develop therapeutic resistance to androgen blockade, and it has recently been suggested that patients should receive at least three different lines of treatment. ${ }^{356}$

\section{Radioisotopes}

Therapeutic radioisotopes with high affinity for bones such as phosphorus-32 have long been used to treat metastatic breast and prostate cancers. ${ }^{357}$ These radioisotopes can emit $\alpha$ - or $\beta$-particles and deliver detrimental radiation to cancer cells. The vast majority of radioisotopes harbor different physical properties, allowing them to address different clinical implications. The most commonly used $\beta$-emitting radioisotopes to treat bone metastases are strontium-89 $\left({ }^{89} \mathrm{Sr}\right)$ and samarium-135 $\left({ }^{135} \mathrm{Sm}\right)$. In one study, prostate cancer patients with bone metastases randomly received either ${ }^{89} \mathrm{Sr}$, a highenergy $\beta$-emitting radioisotope, or external beam radiation. Both types of treatment were effective, whereas the ${ }^{89} \mathrm{Sr}$ treatment showed more effective relief of bone pain. ${ }^{358}$ Compared with ${ }^{89} \mathrm{Sr}$, ${ }^{135} \mathrm{Sm}$ has a shorter half-life, allowing it to be delivered at larger doses with the same treatment time. A meta-analysis suggested that $\beta$-emitting radioisotope therapy alleviates bone pain over 1-6 months but frequently caused severe side effects, including leukopenia and thrombocytopenia. ${ }^{359}$ Moreover, ${ }^{89} \mathrm{Sr}$ and ${ }^{153} \mathrm{Sm}$ are renally excreted, which reduces their efficacy in patients with genitourinary cancers. Radium-223 $\left({ }^{223} \mathrm{Ra}\right)$ is an a-emitting radioisotope abundant in the bone matrix in the area of osteoblastinduced mineralization. In a phase III trial, ${ }^{223}$ Ra prolonged OS in patients with castration-resistant prostate cancer and symptomatic 
bone metastases and was thus approved by the Food and Drug Administration in $2013 .{ }^{360}$ Ongoing clinical trials strive to optimize the treatment of bone metastases by evaluating the combination of radioisotopes with chemotherapy. ${ }^{361-364}$

\section{External beam radiation therapy (EBRT)}

EBRT is a conventional palliative treatment for cancer bone metastases to prevent potential bone fractures and can function synergistically with surgical treatments. This treatment also provides timely control for focal bone pain, with $\sim 50 \%$ of ERBTtreated patients reporting pain relief in 2 weeks. ${ }^{200}$ EBRT is effective even in radioresistant tumors, such as those originating from metastatic sarcoma or RCC. ${ }^{365}$ In the past few decades, multiple studies have compared the efficacy of high-dose, shortfraction radiation with radiation at lower doses and more fractions. Based on these trials, meta-analyses suggest no significant difference in either complete or partial responses between patients treated with hypofractionation or multifractionation EBRT. ${ }^{366-368}$ For example, in a recent study, similar pain-control effects were achieved with a single $8 \mathrm{~Gy}$ fraction and $30 \mathrm{~Gy}$ administered in ten fractions. ${ }^{369}$

\section{Surgery}

One common complication of bone metastases is the large area of osteolytic lesions leading to high fracture risks, especially in breast and renal cancer metastases. ${ }^{370}$ In addition to bone pain as a result of fracture at any location, fracture of long bones such as the femur is more likely to cause disability and may decrease the quality of life and negatively affect prognosis. ${ }^{371-375}$ Prophylactic surgery for potential fracture includes plate osteosynthesis and prosthetic implant insertion. ${ }^{376}$ For maximum efficacy, radiation therapy and embolization are usually combined with surgeries as a local adjuvant treatment. ${ }^{377,378}$ Due to the limited guidelines for cancer bone metastases, ${ }^{379,380}$ many surgeons currently make clinical decisions based on the standard practice for fractures or according to their experience. A recent study provides an algorithm for the treatment of patients with long bone metastatic diseases, suggesting that the characteristics of individual bone lesions should be considered when performing surgical fixations or prosthetic reconstructions. ${ }^{381}$ Percutaneous cementoplasty is frequently adopted to treat bone metastases or to prevent impending fractures in weight-bearing bones. However, the single use of percutaneous cementoplasty is not necessarily curative and is suggested to be preceded by ablative treatment. $^{382}$ Eisenberg et al. described a cervical cancer patient who received magnetic resonance-guided focused ultrasound surgery (MRgFUS) for iliac bone metastasis. ${ }^{383}$ In this case, MRgFUS led to a dramatic reduction in pain, and percutaneous cementoplasty was thus not considered. MRgFUS is a noninvasive surgical procedure that is effective in controlling bone metastasis-related pain in multiple clinical trials. ${ }^{384-386}$

\section{Bisphosphonates}

Bisphosphonates are well known for their high affinity for the surface of bones that undergo bone resorption. Bisphosphonate therapy is commonly used for the long-term treatment of osteolytic and metastatic bone diseases. One classification of bisphosphonates is nitrogen-containing bisphosphonate (N-BP); for example, alendronate (ALN) and zoledronic acid (ZOL) are robust inhibitors of protein isoprenylation, which promotes osteoclast apoptosis. Examples of non-N-BPs include clodronate and etidronate, which induce osteoclast apoptosis by impairing mitochondrial function. ${ }^{387,388}$

In addition to the antiresorptive activity, the antitumor characteristics of bisphosphonates, including the inhibition of tumor cell adhesion and invasion, ${ }^{390,391}$ as well as induction of tumor apoptosis, ${ }^{392}$ have been extensively investigated both in vitro and in vivo. ${ }^{389}$ The antiangiogenic effect of bisphosphonates has been studied in several animal models. ${ }^{393-396}$
Pamidronate and clodronate can both abrogate angiogenesis in breast cancers, potentially by suppressing the expression of VEGF and the accumulation of IGF-1-induced HIF-1a protein. ${ }^{397}$ A recent study investigated connexin (Cx) 43 hemichannels, describing a self-defense mechanism of osteocytes against metastatic breast cancer cells. ${ }^{398}$ Treatment with either ALN or ZOL opens the Cx43 molecular passage between osteocytes and extracellular environments. In vivo studies also suggest that bisphosphonates could reduce tumor burden and bone metastasis formation in a dosedependent manner. ${ }^{399}$

Randomized clinical trials evaluated the safety profile and the efficacy of pamidronate to prevent bone metastases in patients with breast cancer. ${ }^{400,401}$ The first skeletal-related event (SRE) was chosen as the primary outcome, and the number of SREs per year was recorded. The pamidronate-treated patients had fewer SREs per year and a longer time to the first SRE than those in the control group. In a phase II/III clinical study, patients with osteolytic lesions secondary to multiple myeloma or metastatic breast cancer were treated with pamidronate and ZOL to define the optimal dose of these two agents. ${ }^{402,403}$ The oral administration of clodronate prevented SREs. ${ }^{404}$ In female patients with primary breast cancer, the treatment of clodronate significantly reduced bone metastases during the 5 -year follow-up. ${ }^{405}$ The oral administration of clodronate has also been reported to reduce both symptomatic progression and death in male patients with hormone-responsive diseases. ${ }^{406}$ ADT, as described above, may decrease the bone mineral density in prostate cancer patients and thus requires the application of bisphosphonates. ${ }^{407}$ Although osteoblastic bone metastases are frequently observed in patients with prostate cancer, the potent efficacy of bisphosphonates in these patients demonstrates the increased osteoclast activities in osteoblastic bone metastases. ${ }^{408}$ One of the side effects of bisphosphonates is osteonecrosis of the jaw (ONJ), which is associated with drug-exposed bone in the oral cavity. ${ }^{409}$ Due to the high dose of bisphosphonates in the treatment, more than $95 \%$ of patients with bone metastases present ONJ. ${ }^{410}$ In the case of ONJ, conservative treatments, including antibiotics and mouth rinses, are recommended. ${ }^{411}$

The combination of bisphosphonates and chemotherapy has also been studied. ZOL increased tumor cell apoptosis in vitro when administered after doxorubicin, possibly due to increased uptake of bisphosphonates caused by chemotherapy. ${ }^{412} \mathrm{~A}$ randomized phase II trial is currently testing the synergy of ZOL and 5-fluorouracil-epirubicin-cyclophosphamide in a neoadjuvant setting. ${ }^{413}$ Combined treatment with third-generation NBP (YM529) and IFN- $a$ inhibited the aggravation of established bone metastases in the RCC model, which is probably mediated by the inhibition of YM529 on osteoclast activation and the antiangiogenic effect of IFN-a. ${ }^{414}$

Novel therapies

Following the identification of the vicious cycle of bone metastases, novel agents that specifically target the complex pathways in bone metastases have been developed, many of which are currently under clinical evaluation. The target inhibition of pathways involved in bone metastases is presented in Fig. 3.

RANK/RANKL signaling is an essential strategy for blocking targets for osteolytic bone diseases. Denosumab, a humanized RANKL antibody and the first drug of this class, has demonstrated superiority over ZOL in preventing bone diseases in both breast and prostate cancers with bone metastases. ${ }^{415,416}$ Denosumab prevents the RANKL/RANK interaction by mimicking the action of OPG and thus reduces the survival and bone resorption activity of these osteoclasts. ${ }^{417,418}$ Based on the overall satisfactory results of clinical trials, denosumab has now been approved for SRE prevention in patients with cancer. A recent study found that AMG161, an equivalent of denosumab, could block RANKL signaling and the formation of micrometastases in $\mathrm{BM}^{419}$ 


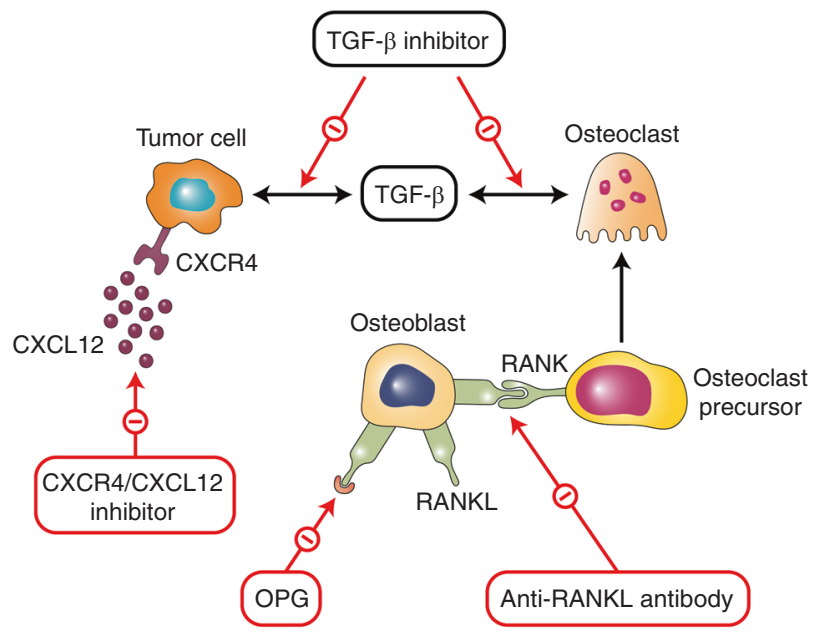

Fig. 3 The target inhibition of pathways involved in bone metastases

As previously discussed, the CXCL12 pathway is an important regulator of metastases in prostate, colorectal, and breast cancers. Blockade of the CXCL12 pathway has been found to substantially delay both primary tumor growth and distant metastasis in multiple preclinical studies. ${ }^{137-141}$ Anti-CXCL12 agents work especially well in the prophylactic setting when treatments start early and are less effective in established tumors. ${ }^{420} \mathrm{~A}$ previous report showed that the pan-VEGFR tyrosine kinase inhibitor cediranib could upregulate circulating $\mathrm{CXCL} 12$ concentrations, ${ }^{421-424}$ and genetic testing results revealed that CXCL12/ CXCR4 pathway activation could lead to the specific inhibition of VEGFR activity in BMDCs. ${ }^{425}$ Therefore, anti-CXCL12 therapy can be used in combination with anti-VEGFR therapies to reach maximum clinical efficacy. Other anticancer treatments are also promising candidates for anti-CXCL12 agents. Several chemotherapeutics, such as paclitaxel or vascular-disrupting agents, can lead to an increased level of circulating CXCL12 and mobilization of BMDCs. ${ }^{426,427}$ Moreover, irradiation upregulates CXCL12 expression, both directly and indirectly, through hypoxia and the related HIF-1 a activation. ${ }^{428-430}$ These results indicate that when used in synergy with other treatment options, anti-CXCL12 therapy demonstrates promising efficacy compared with monotherapy.

TGF- $\beta$ inhibitors represent another class of novel therapies to prevent cancer bone metastases, as more than half of breast cancers display increased TGF- $\beta$ activities. ${ }^{431}$ The inhibition of TGF- $\beta$ has been found in preclinical research to suppress tumor growth and distant metastases, including those to bones, and is highly potent in triple-negative breast cancers. ${ }^{432}$ Many TGF- $\beta$ antagonists, most of which remain at the preclinical stage, are currently under clinical development. These TGF- $\beta$ antagonists include TGF- $\beta$ antibodies (1D11), ${ }^{433-435}$ receptor kinase inhibitors such as LY2109761, ${ }^{249,389,390}$ and other antagonizing agents such as BMP7. ${ }^{389,390}$

HMG-CoA reductase (HMGR) inhibitors have been examined in different cancers (e.g., lung cancer). ${ }^{436}$ HMGR is an important enzyme for cholesterol biosynthesis, ${ }^{437}$ the inhibition of which has demonstrated antitumor effects in multiple tumor types. Simvastatin is an HMGR antagonist and can reduce osteolytic bone metastases of lung cancers, potentially through the downregulation of CD44, P53, and MMPs ${ }^{438}$ or the antagonistic interaction between p53 and CD44. ${ }^{439}$ Furthermore, a thrombin inhibitor, argatroban, could reduce the bone metastasis of breast cancer cells by suppressing the activation of tissue factors and VEGF secretion. ${ }^{440}$ The ET axis is another promising therapeutic target for the treatment of prostate cancer bone metastases. In clinical studies, the ETAR inhibitor atrasentan successfully decreased PSA in male patients with hormone-refractory disease ${ }^{185}$ and markers of bone turnover in prostate cancer patients with bone metastases. $^{441}$

Biological intracontrol treatment (BICT) is an herbal medicinebased therapy involving herbal extracts and palliative care. In a case report, a 59-year-old lung cancer patient who failed first-line chemotherapy treatment and presented with multiple bone metastases was concomitantly treated with BICT and bisphosphonates, which inhibited tumor growth and simultaneously promoted bone repair. ${ }^{442}$ Fish oil has been shown to have a new function, targeting the prometastatic molecule CD44 on the cell surface to suppress the migration and invasion of tumor cells. ${ }^{443}$ Tasquinimod is an experimental drug that has been proven effective in controlling both tumor growth and distant metastases of prostate cancer. ${ }^{444-448}$ The methyl group donor is another drug under experimental evaluation. S-adenosylmethionine has also been found to reduce skeletal metastases both in vitro and in vivo, which probably correlates with increased bone density. ${ }^{449}$ Since bone loss is a severe complication of cancer patients with bone metastases, various bone-anabolic agents that stimulate the synthetic activities of osteoblasts, such as PTH agents, are commonly used in clinical practice. Examples of anabolic agents to prevent bone loss include CaSR antagonists ${ }^{450-452}$ and PTH/ PTHrP. ${ }^{453,454}$

Hypoxic signaling contributes to the preparation of the bone microenvironment for cancer metastases and is therefore an attractive therapeutic target. The inhibition of the hypoxia pathway impairs the development of chemotherapeutic resistance mediated by HIF. A wide variety of hypoxic signaling inhibitors, including the small molecule inhibitor (SMI) 2-methoxyestradiol, ${ }^{455}$ which downregulates HIF-1 a levels and VEGF expression in tumor cells, are under preclinical investigation. ${ }^{456,457}$ Clinical evaluations have also been initiated to assess 2methoxyestradiol and analogs to treat multiple cancers, with the analogs exhibiting more potent antiangiogenic and antitumor effects. $^{458}$ Other examples of SMls that target hypoxic signaling include inhibitors of topoisomerases I and II as well as PI3K inhibitors, which negatively act on HIF-mediated gene transcription. ${ }^{459}$ Based on the interaction between HIF-1 and many other signaling pathways, inhibitors of hypoxic signaling may be used in combination with other therapies to induce sufficient suppression of tumor growth and spread. ${ }^{460}$

\section{CONCLUSION AND PERSPECTIVE}

Bone metastasis is one of the most lethal complications of cancer, and further elucidation of this process should provide new insights into the bone tropism of cancer cells and novel therapies that reduce mortality in cancer patients. Three steps contributing to bone metastases include (1) cancer cell escape and dissemination, (2) adhesion and invasion to bone, and (3) colonization and metastasis in bone. The first step is similar to metastases to nonbone organs, such as the lung and liver, whereas the second and third steps are specific to bone metastases, owing to their distinct cellular and molecular profiles. In particular, bone metastasis involves complex interactions between tumor cells and the bone microenvironment. Thus, the various pathways in the bone microenvironment, such as RANK/RANKL signaling, can be specific therapeutic targets for bone metastases.

In addition to traditional treatments such as hormone therapies, radioisotopes, and bisphosphonates, novel inhibitors that block these pathways, such as the RANKL inhibitors that block osteoclast differentiation, have demonstrated significant antitumor effects in bone metastasis models. It is expected that the concomitant use of novel inhibitors with conventional therapies will provide optimal treatment for bone metastases, but long-term clinical studies are needed to evaluate whether these combinations lead to survival benefits in patients. An in-depth elucidation of the 
premetastatic niche in bone is also essential for the early intervention of bone metastases. However, the majority of studies on the premetastatic bone niche are based on animal models, which may not fully represent the bone microenvironment in humans. Developing animal models that can mimic the general bone metastatic process in human cancers is thus essential. Moreover, elucidating the specific mechanisms for bone metastases in diverse tumors will promote the development of tumortype-specific treatments for bone metastases. Hopefully, the current knowledge and ongoing studies will provide additional alternatives for the treatment of cancer patients with bone metastases.

\section{ACKNOWLEDGEMENTS}

This work is supported by the National Natural Science Foundation of China (reference number: 81602492), the National Key Research and Development Program of China (reference number: 2016YFA0201402), and the National Major Scientific and Technological Special Project for "Significant New Drugs Development" (reference number: 2018ZX09733001).

\section{ADDITIONAL INFORMATION}

Competing interests: The authors declare no competing interests.

\section{REFERENCES}

1. Ruoslahti, E. How cancer spreads. Sci. Am. 275, 72-77 (1996).

2. Rusciano, D. \& Burger, M. M. Why do cancer cells metastasize into particular organs? Bioessays 14, 185-194 (1992).

3. Coleman, R. E. Skeletal complications of malignancy. Cancer 80, 1588-1594 (1997).

4. Kraljevic Pavelic, S., Sedic, M., Bosnjak, H., Spaventi, S. \& Pavelic, K. Metastasis: new perspectives on an old problem. Mol. Cancer 10, 22 (2011).

5. Guise, T. A. The vicious cycle of bone metastases. J. Musculoskelet. Neuronal Interact. 2, 570-572 (2002).

6. Nguyen, D. X., Bos, P. D. \& Massague, J. Metastasis: from dissemination to organspecific colonization. Nat. Rev. Cancer 9, 274-284 (2009).

7. Roodman, G. D. Mechanisms of bone metastasis. N. Engl. J. Med 350, 1655-1664 (2004).

8. Gupta, G. P. \& Massague, J. Cancer metastasis: building a framework. Cell 127, 679-695 (2006).

9. Saki, N., Abroun, S., Farshdousti Hagh, M. \& Asgharei, F. Neoplastic bone marrow niche: hematopoietic and mesenchymal stem cells. Cell J. 13, 131-136 (2011).

10. Chiang, A. C. \& Massague, J. Molecular basis of metastasis. N. Engl. J. Med 359, 2814-2823 (2008).

11. Theriault, R. L. \& Theriault, R. L. Biology of bone metastases. Cancer Control 19, 92-101 (2012).

12. Paget, $\mathrm{S}$. The distribution of secondary growths in cancer of the breast. Cancer Metastasis Rev. 8, 98-101 (1989).

13. Kaplan, R. N. et al. VEGFR1-positive haematopoietic bone marrow progenitors initiate the pre-metastatic niche. Nature 438, 820-827 (2005).

14. Fidler, I. J. The pathogenesis of cancer metastasis: the 'seed and soil' hypothesis revisited. Nat. Rev. Cancer 3, 453-458 (2003).

15. Langley, R. R. \& Fidler, I. J. The seed and soil hypothesis revisited-the role of tumor-stroma interactions in metastasis to different organs. Int. J. Cancer 128, 2527-2535 (2011).

16. Mathot, L. \& Stenninger, J. Behavior of seeds and soil in the mechanism of metastasis: a deeper understanding. Cancer Sci. 103, 626-631 (2012).

17. Peinado, H., Lavotshkin, S. \& Lyden, D. The secreted factors responsible for premetastatic niche formation: old sayings and new thoughts. Semin Cancer Biol. 21, 139-146 (2011)

18. Peinado, H. et al. Pre-metastatic niches: organ-specific homes for metastases. Nat. Rev. Cancer 17, 302-317 (2017).

19. Kitamura, T., Qian, B. Z. \& Pollard, J. W. Immune cell promotion of metastasis. Nat. Rev. Immunol. 15, 73-86 (2015).

20. Kawai, H. et al. Characterization and potential roles of bone marrow-derived stromal cells in cancer development and metastasis. Int. J. Med. Sci. 15, 1406-1414 (2018).

21. Kaplan, R. N., Psaila, B. \& Lyden, D. Bone marrow cells in the 'pre-metastatic niche': within bone and beyond. Cancer Metastasis Rev. 25, 521-529 (2006).

22. Psaila, B. \& Lyden, D. The metastatic niche: adapting the foreign soil. Nat. Rev. Cancer 9, 285-293 (2009).
23. Sahoo, M. et al. Hematopoietic stem cell specific V-ATPase controls breast cancer progression and metastasis via cytotoxic T cells. Oncotarget 9, 33215-33231 (2018).

24. Kaplan, R. N., Rafii, S. \& Lyden, D. Preparing the "soil": the premetastatic niche. Cancer Res. 66, 11089-11093 (2006).

25. Atkins, G. J. \& Findlay, D. M. Osteocyte regulation of bone mineral: a little give and take. Osteoporos. Int. 23, 2067-2079 (2012).

26. Bonewald, L. F. The amazing osteocyte. J. Bone Miner. Res. 26, 229-238 (2011).

27. Winkler, D. G. et al. Osteocyte control of bone formation via sclerostin, a novel BMP antagonist. EMBO J. 22, 6267-6276 (2003).

28. Nakashima, T. et al. Evidence for osteocyte regulation of bone homeostasis through RANKL expression. Nat. Med. 17, 1231-1234 (2011).

29. Xiong, J. et al. Matrix-embedded cells control osteoclast formation. Nat. Med. 17, 1235-1241 (2011).

30. Feng, J. Q. et al. Loss of DMP1 causes rickets and osteomalacia and identifies a role for osteocytes in mineral metabolism. Nat. Genet. 38, 1310-1315 (2006).

31. Kramer, I. et al. Osteocyte $\mathrm{Wnt} /$ beta-catenin signaling is required for normal bone homeostasis. Mol. Cell. Biol. 30, 3071-3085 (2010).

32. Bonewald, L. F. Osteocytes as dynamic multifunctional cells. Ann. N. Y. Acad. Sci. 1116, 281-290 (2007).

33. Quarles, L. D. Skeletal secretion of FGF-23 regulates phosphate and vitamin D metabolism. Nat. Rev. Endocrinol. 8, 276-286 (2012).

34. Lin, H., Sohn, J., Shen, H., Langhans, M. T. \& Tuan, R. S. Bone marrow mesenchymal stem cells: aging and tissue engineering applications to enhance bone healing. Biomaterials 203, 96-110 (2019).

35. Pittenger, M. F. et al. Multilineage potential of adult human mesenchymal stem cells. Science 284, 143-147 (1999).

36. Wakitani, S., Saito, T. \& Caplan, A. I. Myogenic cells derived from rat bone marrow mesenchymal stem cells exposed to 5-azacytidine. Muscle Nerve 18, 1417-1426 (1995).

37. Reyes, M. et al. Purification and ex vivo expansion of postnatal human marrow mesodermal progenitor cells. Blood 98, 2615-2625 (2001).

38. Gao, F. et al. Mesenchymal stem cells and immunomodulation: current status and future prospects. Cell Death Dis. 7, e2062 (2016).

39. Aggarwal, S. \& Pittenger, M. F. Human mesenchymal stem cells modulate allogeneic immune cell responses. Blood 105, 1815-1822 (2005).

40. Dejbakhsh-Jones, S., Jerabek, L., Weissman, I. L. \& Strober, S. Extrathymic maturation of alpha beta T cells from hemopoietic stem cells. J. Immunol. 155, 3338-3344 (1995).

41. Barda-Saad, M., Rozenszajn, L. A., Globerson, A., Zhang, A. S. \& Zipori, D. Selective adhesion of immature thymocytes to bone marrow stromal cells: relevance to $T$ cell lymphopoiesis. Exp. Hematol. 24, 386-391 (1996).

42. Di Nicola, M. et al. Human bone marrow stromal cells suppress T-lymphocyte proliferation induced by cellular or nonspecific mitogenic stimuli. Blood 99, 3838-3843 (2002).

43. Krampera, M. et al. Role for interferon-gamma in the immunomodulatory activity of human bone marrow mesenchymal stem cells. Stem Cells 24, 386-398 (2006).

44. Vlassov, A. V., Magdaleno, S., Setterquist, R. \& Conrad, R. Exosomes: current knowledge of their composition, biological functions, and diagnostic and therapeutic potentials. Biochim. Biophys. Acta 1820, 940-948 (2012).

45. Hoshino, A. et al. Tumour exosome integrins determine organotropic metastasis. Nature 527, 329-335 (2015).

46. Bresnick, A. R., Weber, D. J. \& Zimmer, D. B. S100 proteins in cancer. Nat. Rev. Cancer 15, 96-109 (2015).

47. Zimmer, D. B., Eubanks, J. O., Ramakrishnan, D. \& Criscitiello, M. F. Evolution of the S100 family of calcium sensor proteins. Cell Calcium 53, 170-179 (2013).

48. Moon, A. et al. Global gene expression profiling unveils S100A8/A9 as candidate markers in H-ras-mediated human breast epithelial cell invasion. Mol. Cancer Res. 6, 1544-1553 (2008).

49. Kagan, H. M. \& Trackman, P. C. Properties and function of lysyl oxidase. Am. J. Respir. Cell Mol. Biol. 5, 206-210 (1991).

50. Levental, K. R. et al. Matrix crosslinking forces tumor progression by enhancing integrin signaling. Cell 139, 891-906 (2009).

51. Reynaud, C. et al. Lysyl oxidase is a strong determinant of tumor cell colonization in bone. Cancer Res. 77, 268-278 (2017).

52. Cox, T. R. et al. The hypoxic cancer secretome induces pre-metastatic bone lesions through lysyl oxidase. Nature 522, 106-110 (2015).

53. Monteiro, A. C. et al. T cells induce pre-metastatic osteolytic disease and help bone metastases establishment in a mouse model of metastatic breast cancer. PLOS ONE 8, e68171 (2013).

54. Barker, H. E., Cox, T. R. \& Erler, J. T. The rationale for targeting the LOX family in cancer. Nat. Rev. Cancer 12, 540-552 (2012).

55. Cox, T. R., Gartland, A. \& Erler, J. T. Lysyl Oxidase, a targetable secreted molecule involved in cancer metastasis. Cancer Res. 76, 188-192 (2016). 
56. Sun, W. et al. Osteoclast-derived microRNA-containing exosomes selectively inhibit osteoblast activity. Cell Discov. 2, 16015 (2016)

57. Deng, L. et al. Osteoblast-derived microvesicles: a novel mechanism for communication between osteoblasts and osteoclasts. Bone 79, 37-42 (2015).

58. Zhang, H. C. et al. Microvesicles derived from human umbilical cord mesenchymal stem cells stimulated by hypoxia promote angiogenesis both in vitro and in vivo. Stem Cells Dev. 21, 3289-3297 (2012).

59. Huynh, N. et al. Characterization of regulatory extracellular vesicles from osteoclasts. J. Dent. Res. 95, 673-679 (2016).

60. Yuan, F. L. et al. Osteoclast-derived extracellular vesicles: novel regulators of osteoclastogenesis and osteoclast-osteoblasts communication in bone remodeling. Front. Physiol. 9, 628 (2018).

61. Li, D. et al. Osteoclast-derived exosomal miR-214-3p inhibits osteoblastic bone formation. Nat. Commun. 7, 10872 (2016).

62. Harris, A. L. Hypoxia-a key regulatory factor in tumour growth. Nat. Rev. Cancer 2, 38-47 (2002).

63. Le, Q. T., Denko, N. C. \& Giaccia, A. J. Hypoxic gene expression and metastasis. Cancer Metastasis Rev. 23, 293-310 (2004).

64. Arnett, T. Regulation of bone cell function by acid-base balance. Proc. Nutr. Soc. 62, 511-520 (2003).

65. Gatenby, R. A., Gawlinski, E. T., Gmitro, A. F., Kaylor, B. \& Gillies, R. J. Acidmediated tumor invasion: a multidisciplinary study. Cancer Res. 66, 5216-5223 (2006).

66. Hamaoka, T., Madewell, J. E., Podoloff, D. A., Hortobagyi, G. N. \& Ueno, N. T. Bone imaging in metastatic breast cancer. J. Clin. Oncol. 22, 2942-2953 (2004).

67. Taichman, R. S. et al. GAS6 receptor status is associated with dormancy and bone metastatic tumor formation. PLOS ONE 8, e61873 (2013).

68. Roato, I. Bone metastases: when and how lung cancer interacts with bone. World J. Clin. Oncol. 5, 149-155 (2014).

69. Lu, X. et al. VCAM-1 promotes osteolytic expansion of indolent bone micrometastasis of breast cancer by engaging alpha4beta1-positive osteoclast progenitors. Cancer Cell 20, 701-714 (2011).

70. Muto, A. et al. Lineage-committed osteoclast precursors circulate in blood and settle down into bone. J. Bone Miner. Res. 26, 2978-2990 (2011).

71. Lee, A. W. \& States, D. J. Both src-dependent and -independent mechanisms mediate phosphatidylinositol 3-kinase regulation of colony-stimulating factor 1activated mitogen-activated protein kinases in myeloid progenitors. Mol. Cell. Biol. 20, 6779-6798 (2000).

72. Dougall, W. C. Molecular pathways: osteoclast-dependent and osteoclastindependent roles of the RANKL/RANK/OPG pathway in tumorigenesis and metastasis. Clin. Cancer Res. 18, 326-335 (2012).

73. Dougall, W. C., Holen, I. \& Gonzalez Suarez, E. Targeting RANKL in metastasis. Bonekey Rep. 3, 519 (2014).

74. Anderson, D. M. et al. A homologue of the TNF receptor and its ligand enhance T-cell growth and dendritic-cell function. Nature 390, 175-179 (1997).

75. $\mathrm{Li}$, J. et al. RANK is the intrinsic hematopoietic cell surface receptor that controls osteoclastogenesis and regulation of bone mass and calcium metabolism. Proc. Natl Acad. Sci. USA 97, 1566-1571 (2000).

76. Santini, D. et al. Receptor activator of NF-kB (RANK) expression in primary tumors associates with bone metastasis occurrence in breast cancer patients PLOS ONE 6, e19234 (2011).

77. Jones, D. H. et al. Regulation of cancer cell migration and bone metastasis by RANKL. Nature 440, 692-696 (2006).

78. Suda, T. et al. Modulation of osteoclast differentiation and function by the new members of the tumor necrosis factor receptor and ligand families. Endocr. Rev. 20, 345-357 (1999).

79. Takahashi, N., Udagawa, N. \& Suda, T. A new member of tumor necrosis factor ligand family, ODF/OPGL/TRANCE/RANKL, regulates osteoclast differentiation and function. Biochem. Biophys. Res. Commun. 256, 449-455 (1999).

80. Maeda, K. et al. Wnt5a-Ror2 signaling between osteoblast-lineage cells and osteoclast precursors enhances osteoclastogenesis. Nat. Med. 18, 405-412 (2012).

81. Karst, M., Gorny, G., Galvin, R. J. \& Oursler, M. J. Roles of stromal cell RANKL, OPG, and M-CSF expression in biphasic TGF-beta regulation of osteoclast differentiation. J. Cell. Physiol. 200, 99-106 (2004).

82. Hodge, J. M., Collier, F. M., Pavlos, N. J., Kirkland, M. A. \& Nicholson, G. C. M-CSF potently augments RANKL-induced resorption activation in mature human osteoclasts. PLOS ONE 6, e21462 (2011).

83. Naito, A. et al. Severe osteopetrosis, defective interleukin-1 signalling and lymph node organogenesis in TRAF6-deficient mice. Genes Cells 4, 353-362 (1999).

84. Armstrong, A. P. et al. A RANK/TRAF6-dependent signal transduction pathway is essential for osteoclast cytoskeletal organization and resorptive function. J. Biol. Chem. 277, 44347-44356 (2002).

85. Hu, R. et al. Eos, MITF, and PU.1 recruit corepressors to osteoclast-specific genes in committed myeloid progenitors. Mol. Cell. Biol. 27, 4018-4027 (2007).
86. Taguchi, Y., Gohda, J., Koga, T., Takayanagi, H. \& Inoue, J. A unique domain in RANK is required for Gab2 and PLCgamma2 binding to establish osteoclastogenic signals. Genes Cells 14, 1331-1345 (2009).

87. Negishi-Koga, T. \& Takayanagi, H. Ca2+-NFATc1 signaling is an essential axis of osteoclast differentiation. Immunol. Rev. 231, 241-256 (2009).

88. Mao, D., Epple, H., Uthgenannt, B., Novack, D. V. \& Faccio, R. PLCgamma2 regulates osteoclastogenesis via its interaction with ITAM proteins and GAB2. J. Clin. Investig. 116, 2869-2879 (2006).

89. Lee, S. H. et al. v-ATPase V0 subunit d2-deficient mice exhibit impaired osteoclast fusion and increased bone formation. Nat. Med. 12, 1403-1409 (2006).

90. Kukita, T. et al. RANKL-induced DC-STAMP is essential for osteoclastogenesis. J. Exp. Med. 200, 941-946 (2004).

91. Yagi, M. et al. DC-STAMP is essential for cell-cell fusion in osteoclasts and foreign body giant cells. J. Exp. Med. 202, 345-351 (2005).

92. Campbell, J. P. et al. Stimulation of host bone marrow stromal cells by sympathetic nerves promotes breast cancer bone metastasis in mice. PLoS Biol. 10, e1001363 (2012).

93. Kakonen, S. M. \& Mundy, G. R. Mechanisms of osteolytic bone metastases in breast carcinoma. Cancer 97, 834-839 (2003).

94. Park, H. R. et al. Expression of osteoprotegerin and RANK ligand in breast cancer bone metastasis. J. Korean Med. Sci. 18, 541-546 (2003).

95. Thomas, R. J. et al. Breast cancer cells interact with osteoblasts to support osteoclast formation. Endocrinology 140, 4451-4458 (1999).

96. Mundy, G. R. Metastasis to bone: causes, consequences and therapeutic opportunities. Nat. Rev. Cancer 2, 584-593 (2002).

97. Powell, G. J. et al. Localization of parathyroid hormone-related protein in breast cancer metastases: increased incidence in bone compared with other sites. Cancer Res. 51, 3059-3061 (1991).

98. Vargas, S. J. et al. Localization of parathyroid hormone-related protein mRNA expression in breast cancer and metastatic lesions by in situ hybridization. J. Bone Miner. Res. 7, 971-979 (1992).

99. Kohno, N. et al. The expression of parathyroid hormone-related protein in human breast cancer with skeletal metastases. Surg. Today 24, 215-220 (1994).

100. Guise, T. A. et al. Evidence for a causal role of parathyroid hormone-related protein in the pathogenesis of human breast cancer-mediated osteolysis. J. Clin. Investig. 98, 1544-1549 (1996).

101. Boyle, W. J., Simonet, W. S. \& Lacey, D. L. Osteoclast differentiation and activation. Nature 423, 337-342 (2003).

102. Lacey, D. L. et al. Bench to bedside: elucidation of the OPG-RANK-RANKL pathway and the development of denosumab. Nat. Rev. Drug Discov. 11 401-419 (2012).

103. Yasuda, $\mathrm{H}$. et al. Identity of osteoclastogenesis inhibitory factor (OCIF) and osteoprotegerin (OPG): a mechanism by which OPG/OCIF inhibits osteoclastogenesis in vitro. Endocrinology 139, 1329-1337 (1998).

104. Roodman, G. D. Biology of osteoclast activation in cancer. J. Clin. Oncol. 19, 3562-3571 (2001)

105. Irie, A. et al. Heparin enhances osteoclastic bone resorption by inhibiting osteoprotegerin activity. Bone 41, 165-174 (2007).

106. Lamoureux, F. et al. Glycosaminoglycans as potential regulators of osteoprotegerin therapeutic activity in osteosarcoma. Cancer Res. 69, 526-536 (2009).

107. Corey, E. et al. Osteoprotegerin in prostate cancer bone metastasis. Cancer Res. 65, 1710-1718 (2005).

108. Nyambo, R. et al. Human bone marrow stromal cells protect prostate cancer cells from TRAIL-induced apoptosis. J. Bone Miner. Res. 19, 1712-1721 (2004).

109. Holen, I., Croucher, P. I., Hamdy, F. C., Eaton, C. L. \& Osteoprotegerin, O. P. G. is a survival factor for human prostate cancer cells. Cancer Res. 62, 1619-1623 (2002).

110. Brown, J. M. et al. Osteoprotegerin and rank ligand expression in prostate cancer. Urology 57, 611-616 (2001).

111. Tae, C. H. et al. Significance of calcium-sensing receptor expression in gastric cancer. Scand. J. Gastroenterol. 51, 67-72 (2016).

112. Singh, N., Aslam, M. N., Varani, J. \& Chakrabarty, S. Induction of calcium sensing receptor in human colon cancer cells by calcium, vitamin $D$ and aquamin: promotion of a more differentiated, less malignant and indolent phenotype. Mol. Carcinog. 54, 543-553 (2015).

113. Diez-Fraile, A., Lammens, T., Benoit, Y. \& D'Herde, K. G. The calcium-sensing receptor as a regulator of cellular fate in normal and pathological conditions. Curr. Mol. Med. 13, 282-295 (2013).

114. Joeckel, E. et al. High calcium concentration in bones promotes bone metastasis in renal cell carcinomas expressing calcium-sensing receptor. Mol. Cancer 13, 42 (2014).

115. Zekri, J., Ahmed, N., Coleman, R. E. \& Hancock, B. W. The skeletal metastatic complications of renal cell carcinoma. Int. J. Oncol. 19, 379-382 (2001).

116. Frees, S. et al. Calcium-sensing receptor (CaSR) promotes development of bone metastasis in renal cell carcinoma. Oncotarget 9, 15766-15779 (2018). 
117. Boudot, C. et al. Overexpression of a functional calcium-sensing receptor dramatically increases osteolytic potential of MDA-MB-231 cells in a mouse model of bone metastasis through epiregulin-mediated osteoprotegerin downregulation. Oncotarget 8, 56460-56472 (2017).

118. Wu, Y. \& Zhou, B. P. TNF-alpha/NF-kappaB/snail pathway in cancer cell migration and invasion. Br. J. Cancer 102, 639-644 (2010).

119. Ji, $\mathrm{H}$. et al. TNFR1 mediates TNF-alpha-induced tumour lymphangiogenesis and metastasis by modulating VEGF-C-VEGFR3 signalling. Nat. Commun. 5, 4944 (2014).

120. Calcinotto, A. et al. Targeting TNF-alpha to neoangiogenic vessels enhances lymphocyte infiltration in tumors and increases the therapeutic potential of immunotherapy. J. Immunol. 188, 2687-2694 (2012).

121. Ikemoto, S. et al. TNF alpha, IL-1 beta and IL-6 production by peripheral blood monocytes in patients with renal cell carcinoma. Anticancer Res. 20, 317-321 (2000).

122. Balkwill, F. \& Joffroy, C. TNF: a tumor-suppressing factor or a tumor-promoting factor? Future Oncol. 6, 1833-1836 (2010).

123. Walsh, M. C. et al. Osteoimmunology: interplay between the immune system and bone metabolism. Annu. Rev. Immunol. 24, 33-63 (2006).

124. Kitaura, H. et al. Immunological reaction in TNF-alpha-mediated osteoclast formation and bone resorption in vitro and in vivo. Clin. Dev. Immunol. 2013, 181849 (2013).

125. Kitaura, H. et al. M-CSF mediates TNF-induced inflammatory osteolysis. J. Clin. Investig. 115, 3418-3427 (2005)

126. Weitzmann, M. N., Cenci, S., Rifas, L., Brown, C. \& Pacifici, R. Interleukin-7 stimulates osteoclast formation by up-regulating the T-cell production of soluble osteoclastogenic cytokines. Blood 96, 1873-1878 (2000).

127. Komine, M. et al. Tumor necrosis factor-alpha cooperates with receptor activator of nuclear factor kappaB ligand in generation of osteoclasts in stromal celldepleted rat bone marrow cell culture. Bone 28, 474-483 (2001).

128. Azuma, Y., Kaji, K., Katogi, R., Takeshita, S. \& Kudo, A. Tumor necrosis factor-alpha induces differentiation of and bone resorption by osteoclasts. J. Biol. Chem. 275, 4858-4864 (2000).

129. Kanazawa, K., Azuma, Y., Nakano, H. \& Kudo, A. TRAF5 functions in both RANKLand TNFalpha-induced osteoclastogenesis. J. Bone Miner. Res. 18, 443-450 (2003).

130. Kanazawa, K. \& Kudo, A. TRAF2 is essential for TNF-alpha-induced osteoclastogenesis. J. Bone Miner. Res. 20, 840-847 (2005).

131. Zhang, Y. H., Heulsmann, A., Tondravi, M. M., Mukherjee, A. \& Abu-Amer, Y. Tumor necrosis factor-alpha (TNF) stimulates RANKL-induced osteoclastogenesis via coupling of TNF type 1 receptor and RANK signaling pathways. J. Biol. Chem. 276, 563-568 (2001)

132. Yao, Z. et al. RANKL cytokine enhances TNF-induced osteoclastogenesis independently of TNF receptor associated factor (TRAF) 6 by degrading TRAF3 in osteoclast precursors. J. Biol. Chem. 292, 10169-10179 (2017).

133. Hwang, S. J. et al. Interleukin-34 produced by human fibroblast-like synovial cells in rheumatoid arthritis supports osteoclastogenesis. Arthritis Res Ther. 14, R14 (2012).

134. Corrado, A., Neve, A., Maruotti, N. \& Cantatore, F. P. Bone effects of biologic drugs in rheumatoid arthritis. Clin. Dev. Immunol. 2013, 945945 (2013).

135. Tani-Ishii, N., Tsunoda, A., Teranaka, T. \& Umemoto, T. Autocrine regulation of osteoclast formation and bone resorption by IL-1 alpha and TNF alpha. J. Dent. Res. 78, 1617-1623 (1999).

136. Sunyer, T., Lewis, J., Collin-Osdoby, P. \& Osdoby, P. Estrogen's bone-protective effects may involve differential IL-1 receptor regulation in human osteoclast-like cells. J. Clin. Investig. 103, 1409-1418 (1999).

137. Kim, J. H. et al. The mechanism of osteoclast differentiation induced by IL-1. J. Immunol.183, 1862-1870 (2009).

138. Jules, J. et al. Molecular basis of requirement of receptor activator of nuclear factor kappaB signaling for interleukin 1-mediated osteoclastogenesis. J. Biol. Chem. 287, 15728-15738 (2012).

139. Ruscitti, P. et al. The role of IL-1 beta in the bone loss during rheumatic diseases. Mediators Inflamm. 2015, 782382 (2015).

140. Wei, S., Kitaura, H., Zhou, P., Ross, F. P. \& Teitelbaum, S. L. IL-1 mediates TNFinduced osteoclastogenesis. J. Clin. Investig. 115, 282-290 (2005).

141. Dinarello, C. A., Simon, A. \& van der Meer, J. W. Treating inflammation by blocking interleukin-1 in a broad spectrum of diseases. Nat. Rev. Drug Discov. 11, 633-652 (2012)

142. Rose-John, S. Interleukin-6 family cytokines. Cold Spring Harb. Perspect. Biol. 10, a028415 (2018)

143. Yoshitake, F., Itoh, S., Narita, H., Ishihara, K. \& Ebisu, S. Interleukin-6 directly inhibits osteoclast differentiation by suppressing receptor activator of NFkappaB signaling pathways. J. Biol. Chem. 283, 11535-11540 (2008).

144. Kudo, O. et al. Interleukin-6 and interleukin-11 support human osteoclast formation by a RANKL-independent mechanism. Bone 32, 1-7 (2003).
145. Wakabayashi, H. et al. Interleukin- 6 receptor inhibitor suppresses bone metastases in a breast cancer cell line. Breast Cancer 25, 566-574 (2018).

146. Amarasekara, D. S. et al. Regulation of osteoclast differentiation by cytokine networks. Immune Netw. 18, e8 (2018).

147. Feng, W. et al. Combination of IL-6 and sIL-6R differentially regulate varying levels of RANKL-induced osteoclastogenesis through NF-kappaB, ERK and JNK signaling pathways. Sci. Rep. 7, 41411 (2017).

148. Heinrich, P. C. et al. Principles of interleukin (IL)-6-type cytokine signalling and its regulation. Biochem. J. 374, 1-20 (2003).

149. Argast, G. M. et al. Cooperative signaling between oncostatin M, hepatocyte growth factor and transforming growth factor-beta enhances epithelial to mesenchymal transition in lung and pancreatic tumor models. Cells Tissues Organs 193, 114-132 (2011).

150. Holzer, R. G., Ryan, R. E., Tommack, M., Schlekeway, E. \& Jorcyk, C. L. Oncostatin $M$ stimulates the detachment of a reservoir of invasive mammary carcinoma cells: role of cyclooxygenase-2. Clin. Exp. Metastasis 21, 167-176 (2004).

151. Jorcyk, C. L., Holzer, R. G. \& Ryan, R. E. Oncostatin M induces cell detachment and enhances the metastatic capacity of T-47D human breast carcinoma cells. Cytokine 33, 323-336 (2006).

152. Hui, W., Rowan, A. D., Richards, C. D. \& Cawston, T. E. Oncostatin M in combination with tumor necrosis factor alpha induces cartilage damage and matrix metalloproteinase expression in vitro and in vivo. Arthritis Rheum. 48 , 3404-3418 (2003).

153. Bolin, C. et al. Oncostatin M promotes mammary tumor metastasis to bone and osteolytic bone degradation. Genes Cancer 3, 117-130 (2012).

154. Aguila, H. L. et al. Osteoblast-specific overexpression of human interleukin-7 rescues the bone mass phenotype of interleukin-7-deficient female mice. J. Bone Miner. Res. 27, 1030-1042 (2012).

155. Toraldo, G., Roggia, C., Qian, W. P., Pacifici, R. \& Weitzmann, M. N. IL-7 induces bone loss in vivo by induction of receptor activator of nuclear factor kappa $B$ ligand and tumor necrosis factor alpha from T cells. Proc. Natl Acad. Sci. USA 100, 125-130 (2003).

156. $\mathrm{Yu}$, J. et al. Generation of an osteoblast-based artificial niche that supports in vitro B lymphopoiesis. Exp. Mol. Med. 49, e400 (2017).

157. Roato, I. et al. IL-7 up-regulates TNF-alpha-dependent osteoclastogenesis in patients affected by solid tumor. PLOS ONE 1, e124 (2006).

158. Lubberts, E. et al. IL-17 promotes bone erosion in murine collagen-induced arthritis through loss of the receptor activator of NF-kappa B ligand/osteoprotegerin balance. J. Immunol. 170, 2655-2662 (2003).

159. Kim, J. H. et al. Interleukin-7 induces osteoclast formation via STAT5, independent of receptor activator of NF-kappaB ligand. Front. Immunol. 8, 1376 (2017).

160. Roy, L. D. et al. Systemic neutralization of IL-17A significantly reduces breast cancer associated metastasis in arthritic mice by reducing CXCL12/SDF-1 expression in the metastatic niches. BMC Cancer 14, 225 (2014).

161. Balani, D., Aeberli, D., Hofstetter, W. \& Seitz, M. Interleukin-17A stimulates granulocyte-macrophage colony-stimulating factor release by murine osteoblasts in the presence of 1,25-dihydroxyvitamin $D(3)$ and inhibits murine osteoclast development in vitro. Arthritis Rheum. 65, 436-446 (2013).

162. Shi, Y. et al. Granulocyte-macrophage colony-stimulating factor (GM-CSF) and Tcell responses: what we do and don't know. Cell Res. 16, 126-133 (2006).

163. Lee, M. S. et al. GM-CSF regulates fusion of mononuclear osteoclasts into boneresorbing osteoclasts by activating the Ras/ERK pathway. J. Immunol. 183, 3390-3399 (2009).

164. Ruef, N. et al. Granulocyte-macrophage colony-stimulating factor-dependent CD11c-positive cells differentiate into active osteoclasts. Bone 97, 267-277 (2017).

165. Atanga, E., Dolder, S., Dauwalder, T., Wetterwald, A. \& Hofstetter, W. TNFalpha inhibits the development of osteoclasts through osteoblast-derived GM-CSF. Bone 49, 1090-1100 (2011).

166. Paul, S. R. et al. Molecular cloning of a CDNA encoding interleukin 11, a stromal cell-derived lymphopoietic and hematopoietic cytokine. Proc. Natl Acad. Sci. USA 87, 7512-7516 (1990).

167. Zhang, Y. et al. Production of interleukin-11 in bone-derived endothelial cells and its role in the formation of osteolytic bone metastasis. Oncogene 16, 693-703 (1998).

168. Romas, E. et al. The role of gp130-mediated signals in osteoclast development: regulation of interleukin 11 production by osteoblasts and distribution of its receptor in bone marrow cultures. J. Exp. Med. 183, 2581-2591 (1996).

169. Elias, J. A., Tang, W. \& Horowitz, M. C. Cytokine and hormonal stimulation of human osteosarcoma interleukin-11 production. Endocrinology 136, 489-498 (1995).

170. Girasole, G., Passeri, G., Jilka, R. L. \& Manolagas, S. C. Interleukin-11: a new cytokine critical for osteoclast development. J. Clin. Investig. 93, 1516-1524 (1994). 
171. Ren, L., Wang, X., Dong, Z., Liu, J. \& Zhang, S. Bone metastasis from breast cancer involves elevated IL-11 expression and the gp130/STAT3 pathway. Med. Oncol. 30, 634 (2013).

172. Bendre, M. S. et al. Interleukin-8 stimulation of osteoclastogenesis and bone resorption is a mechanism for the increased osteolysis of metastatic bone disease. Bone 33, 28-37 (2003).

173. Bendre, M. S. et al. Tumor-derived interleukin-8 stimulates osteolysis independent of the receptor activator of nuclear factor-kappaB ligand pathway. Cancer Res. 65, 11001-11009 (2005).

174. Kopesky, P. et al. Autocrine signaling is a key regulatory element during osteoclastogenesis. Biol. Open 3, 767-776 (2014).

175. Liu, Y. et al. Role of IL-8 and its receptor in anti-citrullinated protein antibody mediated osteoclastogenesis in RA. Ann. Rheum. Dis. 75, AB0078 (2016).

176. Bhattacharyya, R. S. \& Stern, P. H. IGF-I and MAP kinase involvement in the stimulatory effects of LNCaP prostate cancer cell conditioned media on cell proliferation and protein synthesis in MC3T3-E1 osteoblastic cells. J. Cell. Biochem. 90, 925-937 (2003).

177. Feeley, B. T. et al. Influence of BMPs on the formation of osteoblastic lesions in metastatic prostate cancer. J. Bone Miner. Res. 20, 2189-2199 (2005).

178. Kitagawa, Y. et al. Vascular endothelial growth factor contributes to prostate cancer-mediated osteoblastic activity. Cancer Res. 65, 10921-10929 (2005).

179. Guise, T. A., Yin, J. J. \& Mohammad, K. S. Role of endothelin-1 in osteoblastic bone metastases. Cancer 97, 779-784 (2003).

180. Smollich, M. \& Wulfing, P. The endothelin axis: a novel target for pharmacotherapy of female malignancies. Curr. Vasc. Pharm. 5, 239-248 (2007).

181. Yin, J. J. et al. A causal role for endothelin-1 in the pathogenesis of osteoblastic bone metastases. Proc. Natl Acad. Sci. USA 100, 10954-10959 (2003).

182. Clines, G. A. et al. Dickkopf homolog 1 mediates endothelin-1-stimulated new bone formation. Mol. Endocrinol. 21, 486-498 (2007).

183. Guise, T. Examining the metastatic niche: targeting the microenvironment Semin Oncol. 37, S2-S14 (2010).

184. Hall, C. L., Bafico, A., Dai, J., Aaronson, S. A. \& Keller, E. T. Prostate cancer cells promote osteoblastic bone metastases through Wnts. Cancer Res. 65, 7554-7560 (2005)

185. Carducci, M. A. et al. Effect of endothelin-A receptor blockade with atrasentan on tumor progression in men with hormone-refractory prostate cancer: a randomized, phase II, placebo-controlled trial. J. Clin. Oncol. 21, 679-689 (2003).

186. Nelson, J. B., Udan, M. S., Guruli, G. \& Pflug, B. R. Endothelin-1 inhibits apoptosis in prostate cancer. Neoplasia 7, 631-637 (2005).

187. Van Sant, C. et al. Endothelin signaling in osteoblasts: global genome view and implication of the calcineurin/NFAT pathway. Mol. Cancer Ther. 6, 253-261 (2007).

188. Bendinelli, P. et al. Microenvironmental stimuli affect Endothelin-1 signaling responsible for invasiveness and osteomimicry of bone metastasis from breast cancer. Biochim. Biophys. Acta 1843, 815-826 (2014).

189. Maroni, P. et al. High SPARC expression starting from dysplasia, associated with breast carcinoma, is predictive for bone metastasis without enhancement of plasma levels. Int. J. Mol. Sci. 16, 28108-28122 (2015).

190. Zhong, X., Wang, H. \& Huang, S. Endothelin-1 induces interleukin-18 expression in human osteoblasts. Arch. Oral. Biol. 59, 289-296 (2014).

191. Matteucci, E. et al. Microenvironment stimuli HGF and hypoxia differently affected miR-125b and Ets-1 function with opposite effects on the invasiveness of bone metastatic cells: a comparison with breast carcinoma cells. Int. J. Mol. Sci. 19, 258 (2018)

192. Hall, C. L. \& Keller, E. T. The role of Wnts in bone metastases. Cancer Metastasis Rev. 25, 551-558 (2006).

193. Zhuang, X. et al. Differential effects on lung and bone metastasis of breast cancer by Wnt signalling inhibitor DKK1. Nat. Cell Biol. 19, 1274-1285 (2017).

194. Kasoha, M. et al. Dickkopf-1 (Dkk1) protein expression in breast cancer with special reference to bone metastases. Clin. Exp. Metastasis 35, 763-775 (2018).

195. Balemans, W. et al. Increased bone density in sclerosteosis is due to the deficiency of a novel secreted protein (SOST). Hum. Mol. Genet. 10, 537-543 (2001).

196. Brunkow, M. E. et al. Bone dysplasia sclerosteosis results from loss of the SOST gene product, a novel cystine knot-containing protein. Am. J. Hum. Genet. 68, 577-589 (2001)

197. Li, X. et al. Sclerostin binds to LRP5/6 and antagonizes canonical Wnt signaling. J. Biol. Chem. 280, 19883-19887 (2005).

198. Glinka, A. et al. LGR4 and LGR5 are R-spondin receptors mediating Wnt/betacatenin and Wnt/PCP signalling. EMBO Rep. 12, 1055-1061 (2011).

199. ten Dijke, P., Krause, C., de Gorter, D. J., Lowik, C. W. \& van Bezooijen, R. L. Osteocyte-derived sclerostin inhibits bone formation: its role in bone morphogenetic protein and Wnt signaling. J. Bone Joint Surg. Am. 90, 31-35 (2008).

200. Clines, G. A. \& Guise, T. A. Molecular mechanisms and treatment of bone metastasis. Expert Rev. Mol. Med. 10, e7 (2008).
201. Liao, J. \& McCauley, L. K. Skeletal metastasis: established and emerging roles of parathyroid hormone related protein (PTHrP). Cancer Metastasis Rev. 25 559-571 (2006).

202. Deftos, L. J., Barken, I., Burton, D. W., Hoffman, R. M. \& Geller, J. Direct evidence that PTHrP expression promotes prostate cancer progression in bone. Biochem. Biophys. Res. Commun. 327, 468-472 (2005).

203. Hoey, R. P. et al. The parathyroid hormone-related protein receptor is expressed in breast cancer bone metastases and promotes autocrine proliferation in breast carcinoma cells. Br. J. Cancer 88, 567-573 (2003).

204. Shen, X. \& Falzon, M. PTH-related protein enhances LoVo colon cancer cell proliferation, adhesion, and integrin expression. Regul. Pept. 125, 17-27 (2005).

205. Massfelder, T. et al. Parathyroid hormone-related protein is an essential growth factor for human clear cell renal carcinoma and a target for the von HippelLindau tumor suppressor gene. Cancer Res. 64, 180-188 (2004).

206. Ma, Y. L. et al. Catabolic effects of continuous human PTH (1-38) in vivo is associated with sustained stimulation of RANKL and inhibition of osteoprotegerin and gene-associated bone formation. Endocrinology 142, 4047-4405 (2001).

207. Liao, J. et al. Tumor expressed PTHrP facilitates prostate cancer-induced osteoblastic lesions. Int. J. Cancer 123, 2267-2278 (2008).

208. LeBeau, A. M., Kostova, M., Craik, C. S. \& Denmeade, S. R. Prostate-specific antigen: an overlooked candidate for the targeted treatment and selective imaging of prostate cancer. Biol. Chem. 391, 333-343 (2010).

209. Cramer, S. D. Chen, Z. \& Peehl, D. M. Prostate specific antigen cleaves parathyroid hormone-related protein in the PTH-like domain: inactivation of PTHrPstimulated cAMP accumulation in mouse osteoblasts. J. Urol. 156, 526-531 (1996).

210. Schluter, K. D., Katzer, C. \& Piper, H. M. A N-terminal PTHrP peptide fragment void of a PTH/PTHrP-receptor binding domain activates cardiac ET(A) receptors. Br. J. Pharmacol. 132, 427-432 (2001).

211. Fielder, P. J. et al. Biochemical analysis of prostate specific antigen-proteolyzed insulin-like growth factor binding protein-3. Growth Regul. 4, 164-172 (1994).

212. Killian, C. S., Corral, D. A., Kawinski, E. \& Constantine, R. I. Mitogenic response of osteoblast cells to prostate-specific antigen suggests an activation of latent TGFbeta and a proteolytic modulation of cell adhesion receptors. Biochem. Biophys. Res. Commun. 192, 940-947 (1993).

213. Williams, S. A., Singh, P., Isaacs, J. T. \& Denmeade, S. R. Does PSA play a role as a promoting agent during the initiation and/or progression of prostate cancer? Prostate 67, 312-329 (2007)

214. Lee, Y. C. et al. BMP4 promotes prostate tumor growth in bone through osteogenesis. Cancer Res. 71, 5194-5203 (2011).

215. Li, Z. G. et al. Androgen receptor-negative human prostate cancer cells induce osteogenesis in mice through FGF9-mediated mechanisms. J. Clin. Investig. 118, 2697-2710 (2008).

216. Chambers, A. F., Groom, A. C. \& MacDonald, I. C. Dissemination and growth of cancer cells in metastatic sites. Nat. Rev. Cancer 2, 563-572 (2002).

217. Johnson, R. W. \& Suva, L. J. Hallmarks of bone metastasis. Calcif. Tissue Int. 102 141-151 (2018)

218. Egeblad, M. \& Werb, Z. New functions for the matrix metalloproteinases in cancer progression. Nat. Rev. Cancer 2, 161-174 (2002).

219. Djonov, V. et al. Tumor cell specific expression of MMP-2 correlates with tumor vascularisation in breast cancer. Int. J. Oncol. 21, 25-30 (2002).

220. Ruokolainen, H., Paakko, P. \& Turpeenniemi-Hujanen, T. Expression of matrix metalloproteinase- 9 in head and neck squamous cell carcinoma: a potential marker for prognosis. Clin. Cancer Res. 10, 3110-3116 (2004).

221. Bachmeier, B. E., Nerlich, A. G., Lichtinghagen, R. \& Sommerhoff, C. P. Matrix metalloproteinases (MMPs) in breast cancer cell lines of different tumorigenicity. Anticancer Res. 21, 3821-3828 (2001).

222. Upadhyay, J. et al. Membrane type 1-matrix metalloproteinase (MT1-MMP) and MMP-2 immunolocalization in human prostate: change in cellular localization associated with high-grade prostatic intraepithelial neoplasia. Clin. Cancer Res. 5, 4105-4110 (1999).

223. Nakopoulou, L. et al. MMP-2 protein in invasive breast cancer and the impact of MMP-2/TIMP-2 phenotype on overall survival. Breast Cancer Res. Treat. 77 145-155 (2003).

224. Ranuncolo, S. M., Armanasco, E., Cresta, C., Bal De Kier Joffe, E. \& Puricelli, L. Plasma MMP-9 (92 kDa-MMP) activity is useful in the follow-up and in the assessment of prognosis in breast cancer patients. Int. J. Cancer 106, 745-751 (2003).

225. Benelli, R. et al. Inhibition of AIDS-Kaposi's sarcoma cell induced endothelial cell invasion by TIMP-2 and a synthetic peptide from the metalloproteinase propeptide: implications for an anti-angiogenic therapy. Oncol. Res. 6, 251-257 (1994).

226. Anand-Apte, B. et al. Inhibition of angiogenesis by tissue inhibitor of metalloproteinase-3. Investig. Ophthalmol. Vis. Sci. 38, 817-823 (1997). 
227. Hiraoka, N., Allen, E., Apel, I. J., Gyetko, M. R. \& Weiss, S. J. Matrix metalloproteinases regulate neovascularization by acting as pericellular fibrinolysins. Cell 95, 365-377 (1998).

228. $\mathrm{Vu}, \mathrm{T}$. H. et al. MMP-9/gelatinase $\mathrm{B}$ is a key regulator of growth plate angiogenesis and apoptosis of hypertrophic chondrocytes. Cell 93, 411-422 (1998).

229. Itoh, T. et al. Reduced angiogenesis and tumor progression in gelatinase Adeficient mice. Cancer Res. 58, 1048-1051 (1998).

230. Schnaper, H. W. et al. Type IV collagenase(s) and TIMPs modulate endothelial cell morphogenesis in vitro. J. Cell. Physiol. 156, 235-246 (1993).

231. Jezierska, A. \& Motyl, T. Matrix metalloproteinase- 2 involvement in breast cancer progression: a mini-review. Med. Sci. Monit. 15, RA32-40 (2009).

232. Talvensaari-Mattila, A., Paakko, P. \& Turpeenniemi-Hujanen, T. Matrix metalloproteinase-2 (MMP-2) is associated with survival in breast carcinoma. $B r$. J. Cancer 89, 1270-1275 (2003).

233. Chen, Y., Wang, X., Chen, G., Dong, C. \& Zhang, D. The impact of matrix metalloproteinase 2 on prognosis and clinicopathology of breast cancer patients: a systematic meta-analysis. PLOS ONE 10, e0121404 (2015).

234. Hashimoto, G. et al. Matrix metalloproteinases cleave connective tissue growth factor and reactivate angiogenic activity of vascular endothelial growth factor 165. J. Biol. Chem. 277, 36288-36295 (2002).

235. Chetty, C., Lakka, S. S., Bhoopathi, P. \& Rao, J. S. MMP-2 alters VEGF expression via alphaVbeta3 integrin-mediated PI3K/AKT signaling in A549 lung cancer cells. Int. J. Cancer 127, 1081-1095 (2010).

236. Heroult, M. et al. Heparin affin regulatory peptide binds to vascular endothelial growth factor (VEGF) and inhibits VEGF-induced angiogenesis. Oncogene 23, 1745-1753 (2004).

237. O'Reilly, M. S. et al. Endostatin: an endogenous inhibitor of angiogenesis and tumor growth. Cell 88, 277-285 (1997).

238. Ramchandran, R. et al. Antiangiogenic activity of restin, NC10 domain of human collagen XV: comparison to endostatin. Biochem. Biophys. Res. Commun. 255, 735-739 (1999).

239. Colorado, P. C. et al. Anti-angiogenic cues from vascular basement membrane collagen. Cancer Res. 60, 2520-2526 (2000).

240. Tauro, M. \& Lynch, C. C. Cutting to the chase: how matrix metalloproteinase-2 activity controls breast-cancer-to-bone metastasis. Cancers 10, 185 (2018).

241. Chen, P. C. et al. Thrombospondin-2 promotes prostate cancer bone metastasis by the up-regulation of matrix metalloproteinase-2 through down-regulating miR-376c expression. J. Hematol. Oncol. 10, 33 (2017).

242. Lynch, C. C. et al. MMP-7 promotes prostate cancer-induced osteolysis via the solubilization of RANKL. Cancer Cell 7, 485-496 (2005).

243. Bruni-Cardoso, A., Johnson, L. C., Vessella, R. L., Peterson, T. E. \& Lynch, C. C. Osteoclast-derived matrix metalloproteinase- 9 directly affects angiogenesis in the prostate tumor-bone microenvironment. Mol. Cancer Res. 8, 459-470 (2010).

244. Wang, C. et al. BMP-6 inhibits MMP-9 expression by regulating heme oxygenase-1 in MCF-7 breast cancer cells. J. Cancer Res. Clin. Oncol. 137, 985-995 (2011).

245. Freije, J. M. et al. Molecular cloning and expression of collagenase-3, a novel human matrix metalloproteinase produced by breast carcinomas. J. Biol. Chem. 269, 16766-16773 (1994).

246. Mauviel, A. Cytokine regulation of metalloproteinase gene expression. J. Cell. Biochem. 53, 288-295 (1993).

247. Johansson, N. et al. Expression of collagenase-3 (matrix metalloproteinase-13) in squamous cell carcinomas of the head and neck. Am. J. Pathol. 151, 499-508 (1997).

248. Cazorla, M. et al. Collagenase-3 expression is associated with advanced local invasion in human squamous cell carcinomas of the larynx. J. Pathol. 186, 144-150 (1998).

249. Ren, X.-F., Mu, L.-P., Jiang, Y.-S., Wang, L. \& Ma, J.-F. LY2109761 inhibits metastasis and enhances chemosensitivity in osteosarcoma MG-63 cells. Eur. Rev. Med. Pharmacol. 19(7), 1182-1190 (2015).

250. Wang, J., Loberg, R. \& Taichman, R. S. The pivotal role of CXCL12 (SDF-1)/CXCR4 axis in bone metastasis. Cancer Metastasis Rev. 25, 573-587 (2006).

251. Sun, X. et al. CXCL12/CXCR4/CXCR7 chemokine axis and cancer progression. Cancer Metastasis Rev. 29, 709-722 (2010).

252. Muller, A. et al. Involvement of chemokine receptors in breast cancer metastasis. Nature 410, 50-56 (2001).

253. Kojima, Y. et al. Autocrine TGF-beta and stromal cell-derived factor-1 (SDF-1) signaling drives the evolution of tumor-promoting mammary stromal myofibroblasts. Proc. Natl Acad. Sci. USA 107, 20009-20014 (2010).

254. Balkwill, F. Cancer and the chemokine network. Nat. Rev. Cancer 4, 540-550 (2004).

255. Hattermann, K. et al. The chemokine receptor CXCR7 is highly expressed in human glioma cells and mediates antiapoptotic effects. Cancer Res. 70, 3299-3308 (2010).
256. Miao, Z. et al. CXCR7 (RDC1) promotes breast and lung tumor growth in vivo and is expressed on tumor-associated vasculature. Proc. Natl Acad. Sci. USA 104, 15735-15740 (2007).

257. Orimo, A. et al. Stromal fibroblasts present in invasive human breast carcinomas promote tumor growth and angiogenesis through elevated SDF-1/ CXCL12 secretion. Cell 121, 335-348 (2005).

258. Kishimoto, $\mathrm{H}$. et al. The p160 family coactivators regulate breast cancer cell proliferation and invasion through autocrine/paracrine activity of SDF-1alpha/ CXCL12. Carcinogenesis 26, 1706-1715 (2005).

259. Burger, J. A. \& Kipps, T. J. CXCR4: a key receptor in the crosstalk between tumor cells and their microenvironment. Blood 107, 1761-1767 (2006).

260. Sun, Y. X. et al. Skeletal localization and neutralization of the SDF-1(CXCL12)/ CXCR4 axis blocks prostate cancer metastasis and growth in osseous sites in vivo. J. Bone Miner. Res. 20, 318-329 (2005).

261. Taichman, R. S. et al. Use of the stromal cell-derived factor-1/CXCR4 pathway in prostate cancer metastasis to bone. Cancer Res. 62, 1832-1837 (2002).

262. Singh, S., Srivastava, S. K., Bhardwaj, A., Owen, L. B. \& Singh, A. P. CXCL12-CXCR4 signalling axis confers gemcitabine resistance to pancreatic cancer cells: a novel target for therapy. Br. J. Cancer 103, 1671-1679 (2010).

263. Maderna, E., Salmaggi, A., Calatozzolo, C., Limido, L. \& Pollo, B. Nestin, PDGFRbeta, CXCL12 and VEGF in glioma patients: different profiles of (proangiogenic) molecule expression are related with tumor grade and may provide prognostic information. Cancer Biol. Ther. 6, 1018-1024 (2007).

264. Xu, L. et al. Direct evidence that bevacizumab, an anti-VEGF antibody, upregulates SDF1alpha, CXCR4, CXCL6, and neuropilin 1 in tumors from patients with rectal cancer. Cancer Res. 69, 7905-7910 (2009).

265. Engl, T. et al. CXCR4 chemokine receptor mediates prostate tumor cell adhesion through alpha5 and beta3 integrins. Neoplasia 8, 290-301 (2006).

266. Havens, A. M. et al. The role of sialomucin CD164 (MGC-24v or endolyn) in prostate cancer metastasis. BMC Cancer 6, 195 (2006).

267. Cabioglu, N. et al. CXCL-12/stromal cell-derived factor-1alpha transactivates HER2-neu in breast cancer cells by a novel pathway involving Src kinase activation. Cancer Res. 65, 6493-6497 (2005).

268. Kang, Y. et al. A multigenic program mediating breast cancer metastasis to bone. Cancer Cell 3, 537-549 (2003).

269. Liang, Z. et al. Silencing of CXCR4 blocks breast cancer metastasis. Cancer Res. 65, 967-971 (2005)

270. Richert, M. M. et al. Inhibition of CXCR4 by CTCE-9908 inhibits breast cancer metastasis to lung and bone. Oncol. Rep. 21, 761-767 (2009).

271. Chinni, S. R. et al. CXCL12/CXCR4 signaling activates Akt-1 and MMP-9 expression in prostate cancer cells: the role of bone microenvironment-associated CXCL12. Prostate 66, 32-48 (2006).

272. Wang, J. et al. Diverse signaling pathways through the SDF-1/CXCR4 chemokine axis in prostate cancer cell lines leads to altered patterns of cytokine secretion and angiogenesis. Cell Signal. 17, 1578-1592 (2005).

273. Glinskii, O. V. et al. Mechanical entrapment is insufficient and intercellular adhesion is essential for metastatic cell arrest in distant organs. Neoplasia 7, 522-527 (2005).

274. Glinsky, V. V. et al. The role of Thomsen-Friedenreich antigen in adhesion of human breast and prostate cancer cells to the endothelium. Cancer Res. 61, 4851-4857 (2001).

275. Hill, A., McFarlane, S., Johnston, P. G. \& Waugh, D. J. The emerging role of CD44 in regulating skeletal micrometastasis. Cancer Lett. 237, 1-9 (2006).

276. Pinilla, S. et al. Tissue resident stem cells produce CCL5 under the influence of cancer cells and thereby promote breast cancer cell invasion. Cancer Lett. 284, 80-85 (2009).

277. Karnoub, A. E. et al. Mesenchymal stem cells within tumour stroma promote breast cancer metastasis. Nature 449, 557-563 (2007).

278. Urata, S. et al. C-C motif ligand 5 promotes migration of prostate cancer cells in the prostate cancer bone metastasis microenvironment. Cancer Sci. 109, 724-731 (2018).

279. Kim, M. et al. The lymphotactin receptor is expressed in epithelial ovarian carcinoma and contributes to cell migration and proliferation. Mol. Cancer Res. 10, 1419-1429 (2012).

280. Khurram, S. A. et al. Functional expression of the chemokine receptor XCR1 on oral epithelial cells. J. Pathol. 221, 153-163 (2010).

281. Gantsev, S. K. et al. The role of inflammatory chemokines in lymphoid neoorganogenesis in breast cancer. Biomed. Pharmacother. 67, 363-366 (2013).

282. Sun, Y. X. et al. Expression and activation of alpha $v$ beta 3 integrins by SDF-1/ CXC12 increases the aggressiveness of prostate cancer cells. Prostate $67,61-73$ (2007).

283. Valcarcel, M. et al. Vascular endothelial growth factor regulates melanoma cell adhesion and growth in the bone marrow microenvironment via tumor cyclooxygenase-2. J. Transl. Med. 9, 142 (2011). 
284. Denkert, C. et al. Expression of cyclooxygenase 2 in human malignant melanoma. Cancer Res. 61, 303-308 (2001).

285. Weilbaecher, K. N., Guise, T. A. \& McCauley, L. K. Cancer to bone: a fatal attraction. Nat. Rev. Cancer 11, 411-425 (2011).

286. Mohammad, K. S. et al. Pharmacologic inhibition of the TGF-beta type I receptor kinase has anabolic and anti-catabolic effects on bone. PLoS ONE 4, e5275 (2009).

287. Korpal, M. et al. Imaging transforming growth factor-beta signaling dynamics and therapeutic response in breast cancer bone metastasis. Nat. Med. 15, 960-966 (2009).

288. Kang, Y. et al. Breast cancer bone metastasis mediated by the Smad tumor suppressor pathway. Proc. Natl Acad. Sci. USA 102, 13909-13914 (2005).

289. Juarez, P. \& Guise, T. A. TGF-beta in cancer and bone: implications for treatment of bone metastases. Bone 48, 23-29 (2011).

290. Serganova, I. et al. Multimodality imaging of TGFbeta signaling in breast cancer metastases. FASEB J. 23, 2662-2672 (2009).

291. Baselga, J. et al. TGF-beta signalling-related markers in cancer patients with bone metastasis. Biomarkers 13, 217-236 (2008).

292. Buijs, J. T. et al. TGF-beta and BMP7 interactions in tumour progression and bone metastasis. Clin. Exp. Metastasis 24, 609-617 (2007).

293. Pickup, M., Novitskiy, S. \& Moses, H. L. The roles of TGFbeta in the tumour microenvironment. Nat. Rev. Cancer 13, 788-799 (2013).

294. Yin, J. J. et al. TGF-beta signaling blockade inhibits PTHrP secretion by breast cancer cells and bone metastases development. J. Clin. Investig. 103, 197-206 (1999).

295. Sethi, N., Dai, X., Winter, C. G. \& Kang, Y. Tumor-derived JAGGED1 promotes osteolytic bone metastasis of breast cancer by engaging notch signaling in bone cells. Cancer Cell 19, 192-205 (2011).

296. Wan, X. et al. Effect of transforming growth factor beta (TGF-beta) receptor kinase inhibitor on prostate cancer bone growth. Bone 50, 695-703 (2012).

297. Kawai, M. \& Rosen, C. J. The insulin-like growth factor system in bone: basic and clinical implications. Endocrinol. Metab. Clin. North Am. 41, 323-333 (2012).

298. Hiraga, T. et al. Bone-derived IGF mediates crosstalk between bone and breast cancer cells in bony metastases. Cancer Res. 72, 4238-4249 (2012).

299. Zhang, X. H. et al. Selection of bone metastasis seeds by mesenchymal signals in the primary tumor stroma. Cell 154, 1060-1073 (2013).

300. Mitsiades, C. S. \& Koutsilieris, M. Molecular biology and cellular physiology of refractoriness to androgen ablation therapy in advanced prostate cancer. Expert Opin. Investig. Drugs 10, 1099-1115 (2001).

301. Koutsilieris, M. et al. A combination therapy of dexamethasone and somatostatin analog reintroduces objective clinical responses to LHRH analog in androgen ablation-refractory prostate cancer patients. J. Clin. Endocrinol. Metab. 86, 5729-5736 (2001)

302. Koutsilieris, M. et al. Combination of dexamethasone and a somatostatin analogue in the treatment of advanced prostate cancer. Expert Opin. Investig. Drugs 11, 283-293 (2002).

303. Koutsilieris, M. et al. Combination of somatostatin analog, dexamethasone, and standard androgen ablation therapy in stage D3 prostate cancer patients with bone metastases. Clin. Cancer Res. 10, 4398-4405 (2004).

304. Bartel, D. P. MicroRNAs: target recognition and regulatory functions. Cell 136, 215-233 (2009).

305. Khew-Goodall, Y. \& Goodall, G. J. Myc-modulated miR-9 makes more metastases. Nat. Cell Biol. 12, 209-211 (2010).

306. Ma, L. et al. miR-9, a MYC/MYCN-activated microRNA, regulates E-cadherin and cancer metastasis. Nat. Cell Biol. 12, 247-256 (2010).

307. Ren, D. et al. Wild-type p53 suppresses the epithelial-mesenchymal transition and stemness in PC-3 prostate cancer cells by modulating miR145. Int. J. Oncol. 42, 1473-1481 (2013)

308. Ren, D. et al. Oncogenic miR-210-3p promotes prostate cancer cell EMT and bone metastasis via NF-kappaB signaling pathway. Mol. Cancer 16, 117 (2017).

309. Colden, M. et al. MicroRNA-466 inhibits tumor growth and bone metastasis in prostate cancer by direct regulation of osteogenic transcription factor RUNX2. Cell Death Dis. 8, e2572 (2017).

310. Siu, M. K. et al. Transforming growth factor-beta promotes prostate bone metastasis through induction of microRNA-96 and activation of the mTOR pathway. Oncogene 34, 4767-4776 (2015).

311. Lou, G. et al. Direct targeting sperm-associated antigen 9 by miR-141 influences hepatocellular carcinoma cell growth and metastasis via JNK pathway. J. Exp. Clin. Cancer Res. : C 35, 14 (2016).

312. Liu, C. et al. MicroRNA-141 suppresses prostate cancer stem cells and metastasis by targeting a cohort of pro-metastasis genes. Nat. Commun. 8, 14270 (2017).

313. Huang, $S$. et al. Downregulation of miR-141-3p promotes bone metastasis via activating NF-kappaB signaling in prostate cancer. J. Exp. Clin. Cancer Res. 36, 173 (2017).
314. Ren, D. et al. Double-negative feedback loop between ZEB2 and miR-145 regulates epithelial-mesenchymal transition and stem cell properties in prostate cancer cells. Cell Tissue Res. 358, 763-778 (2014).

315. Guo, W. et al. HEF1 promotes epithelial mesenchymal transition and bone invasion in prostate cancer under the regulation of microRNA-145. J. Cell. Biochem. 114, 1606-1615 (2013).

316. Huang, S. et al. Transcriptional downregulation of miR-133b by REST promotes prostate cancer metastasis to bone via activating TGF-beta signaling. Cell Death Dis. 9, 779 (2018)

317. Wa, Q. et al. Downregulation of miR19a3p promotes invasion, migration and bone metastasis via activating TGFbeta signaling in prostate cancer. Oncol. Rep. 39, 81-90 (2018).

318. Croset, M., Kan, C. \& Clezardin, P. Tumour-derived miRNAs and bone metastasis. Bonekey Rep. 4, 688 (2015).

319. Taipaleenmaki, $H$. et al. Targeting of Runx 2 by miR-135 and miR-203 Impairs Progression of Breast Cancer and Metastatic Bone Disease. Cancer Res. 75, 1433-1444 (2015)

320. Croset, M. et al. TWIST1 expression in breast cancer cells facilitates bone metastasis formation. J. Bone Miner. Res. 29, 1886-1899 (2014).

321. David, M. et al. Cancer cell expression of autotaxin controls bone metastasis formation in mouse through lysophosphatidic acid-dependent activation of osteoclasts. PLoS ONE 5, e9741 (2010).

322. Leblanc, R. et al. Interaction of platelet-derived autotaxin with tumor integrin alphaVbeta3 controls metastasis of breast cancer cells to bone. Blood 124, 3141-3150 (2014).

323. D'Oronzo, S., Coleman, R., Brown, J. \& Silvestris, F. Metastatic bone disease: pathogenesis and therapeutic options: up-date on bone metastasis management. J. Bone Oncol. 15, 004-4 (2019).

324. Early Breast Cancer Trialists' Collaborative Group. Effects of chemotherapy and hormonal therapy for early breast cancer on recurrence and 15-year survival: an overview of the randomised trials. Lancet 365, 1687-1717 (2005).

325. Early Breast Cancer Trialists' Collaborative Group. Effects of adjuvant tamoxifen and of cytotoxic therapy on mortality in early breast cancer. An overview of 61 randomized trials among 28,896 women. N. Engl. J. Med. 319, 1681-1692 (1988).

326. Pyrhonen, S. et al. Meta-analysis of trials comparing toremifene with tamoxifen and factors predicting outcome of antiestrogen therapy in postmenopausal women with breast cancer. Breast Cancer Res. Treat. 56, 133-143 (1999).

327. Fisher, B. et al. Tamoxifen for prevention of breast cancer: report of the National Surgical Adjuvant Breast and Bowel Project P-1 Study. J. Natl Cancer Inst. 90, 1371-1388 (1998).

328. Cauley, J. A. et al. Continued breast cancer risk reduction in postmenopausal women treated with raloxifene: 4-year results from the MORE trial. Multiple outcomes of raloxifene evaluation. Breast Cancer Res. Treat. 65, 125-134 (2001).

329. Howell, A. et al. Results of the ATAC (Arimidex, Tamoxifen, Alone or in Combination) trial after completion of 5 years' adjuvant treatment for breast cancer. Lancet 365, 60-62 (2005).

330. Coates, A. S. et al. Five years of letrozole compared with tamoxifen as initial adjuvant therapy for postmenopausal women with endocrine-responsive early breast cancer: update of study BIG 1-98. J. Clin. Oncol. 25, 486-492 (2007).

331. Coombes, R. C. et al. Survival and safety of exemestane versus tamoxifen after 23 years' tamoxifen treatment (Intergroup Exemestane Study): a randomised controlled trial. Lancet 369, 559-570 (2007).

332. Arimidex,Tamoxifen, Alone or in Combination (ATAC) Trialists' Group et al.Effect of anastrozole and tamoxifen as adjuvant treatment for early-stage breast cancer: 100-month analysis of the ATAC trial. Lancet Oncol. 9, 45-53 (2008).

333. Buzdar, A. et al. Phase III, multicenter, double-blind, randomized study of letrozole, an aromatase inhibitor, for advanced breast cancer versus megestrol acetate. J. Clin. Oncol. 19, 3357-3366 (2001).

334. Buzdar, A. U. Phase III study of letrozole versus tamoxifen as first-line therapy of advanced breast cancer in postmenopausal women: analysis of survival and update of efficacy from the international letrozole breast cancer group. J. Clin. Oncol. 22, 3199-3200 (2004).

335. Hong, N. et al. Different patterns in the risk of newly developed fatty liver and lipid changes with tamoxifen versus aromatase inhibitors in postmenopausal women with early breast cancer: a propensity score-matched cohort study. Eur. J. Cancer 82, 103-114 (2017).

336. De Placido, S. et al. Adjuvant anastrozole versus exemestane versus letrozole, upfront or after 2 years of tamoxifen, in endocrine-sensitive breast cance (FATA-GIM3): a randomised, phase 3 trial. Lancet Oncol. 19, 474-485 (2018).

337. Early Breast Cancer Trialists' Collaborative Group (EBCTCG). Effects of chemotherapy and hormonal therapy for early breast cancer on recurrence and 15year survival: an overview of the randomised trials. Lancet 365, 1687-1717 (2005). 
338. Coombes, R. C. et al. A randomized trial of exemestane after two to three years of tamoxifen therapy in postmenopausal women with primary breast cancer. $N$. Engl. J. Med. 350, 1081-1092 (2004).

339. Jakesz, R. et al. Switching of postmenopausal women with endocrineresponsive early breast cancer to anastrozole after 2 years' adjuvant tamoxifen: combined results of ABCSG trial 8 and ARNO 95 trial. Lancet 366, 455-462 (2005).

340. Boccardo, F. et al. Switching to anastrozole versus continued tamoxifen treatment of early breast cancer: preliminary results of the Italian Tamoxifen Anastrozole Trial. J. Clin. Oncol. 23, 5138-5147 (2005).

341. Goss, P. E. et al. Randomized trial of letrozole following tamoxifen as extended adjuvant therapy in receptor-positive breast cancer: updated findings from $\mathrm{NCIC}$ CTG MA.17. J. Natl Cancer Inst. 97, 1262-1271 (2005).

342. Mamounas, E. P. Adjuvant exemestane therapy after 5 years of tamoxifen: rationale for the NSABP B-33 trial. Oncology 15, 35-39 (2001).

343. Heshmati, H. M. et al. Role of low levels of endogenous estrogen in regulation of bone resorption in late postmenopausal women. J. Bone Miner. Res. 17, 172-178 (2002).

344. Bouvard, B. et al. Fracture incidence after 3 years of aromatase inhibitor therapy. Ann. Oncol. 25, 843-847 (2014).

345. Heidenreich, A. et al. EAU guidelines on prostate cancer. Part II: treatment of advanced, relapsing, and castration-resistant prostate cancer. Eur. Urol. 65, 467-479 (2014).

346. Huggins, C., Stevens, R. E. Jr. \& Hodges, C. V. Studies on prostatic cancer: ii. The effects of castration on advanced carcinoma of the prostate gland. Arch. Surg. 43, 209-223 (1941).

347. Lepor, H. \& Shore, N. D. LHRH agonists for the treatment of prostate cancer: 2012. Rev. Urol. 14, 1-12 (2012).

348. Hatano, T., Oishi, Y., Furuta, A., Iwamuro, S. \& Tashiro, K. Incidence of bone fracture in patients receiving luteinizing hormone-releasing hormone agonists for prostate cancer. BJU Int. 86, 449-452 (2000)

349. Smith, M. R. et al. Pamidronate to prevent bone loss during androgendeprivation therapy for prostate cancer. N. Engl. J. Med 345, 948-955 (2001).

350. Oefelein, M. G. et al. Skeletal fracture associated with androgen suppression induced osteoporosis: the clinical incidence and risk factors for patients with prostate cancer. J. Urol. 166, 1724-1728 (2001).

351. Melton, L. J. III et al. Fracture risk following bilateral orchiectomy. J. Urol. 169, 1747-1750 (2003).

352. Fizazi, K. et al. Abiraterone acetate for treatment of metastatic castrationresistant prostate cancer: final overall survival analysis of the COU-AA-301 randomised, double-blind, placebo-controlled phase 3 study. Lancet Oncol. 13, 983-992 (2012).

353. Ryan, C. J. et al. Abiraterone acetate plus prednisone versus placebo plus prednisone in chemotherapy-naive men with metastatic castration-resistant prostate cancer (COU-AA-302): final overall survival analysis of a randomised, double-blind, placebo-controlled phase 3 study. Lancet Oncol. 16, 152-160 (2015).

354. Scher, H. I. et al. Increased survival with enzalutamide in prostate cancer after chemotherapy. N. Engl. J. Med. 367, 1187-1197 (2012).

355. Beer, T. M. \& Tombal, B. Enzalutamide in metastatic prostate cancer before chemotherapy. N. Engl. J. Med. 371, 1755-1756 (2014).

356. Sonpavde, G. et al. Sequencing of cabazitaxel and abiraterone acetate after docetaxel in metastatic castration-resistant prostate cancer: treatment patterns and clinical outcomes in multicenter community-based US oncology practices. Clin. Genitourin. Cancer 13, 309-318 (2015).

357. Serafini, A. N. Samarium Sm-153 lexidronam for the palliation of bone pain associated with metastases. Cancer 88, 2934-2939 (2000).

358. Quilty, P. M. et al. A comparison of the palliative effects of strontium-89 and external beam radiotherapy in metastatic prostate cancer. Radiother. Oncol. 31, 33-40 (1994).

359. Roque, I. F. M., Martinez-Zapata, M. J., Scott-Brown, M. \& Alonso-Coello, P. WITHDRAWN: radioisotopes for metastatic bone pain. Cochrane Database Syst. Rev. 3, CD003347 (2017).

360. Hoskin, P. et al. Efficacy and safety of radium-223 dichloride in patients with castration-resistant prostate cancer and symptomatic bone metastases, with or without previous docetaxel use: a prespecified subgroup analysis from the randomised, double-blind, phase 3 ALSYMPCA trial. Lancet Oncol. 15, 1397-1406 (2014).

361. Morris, M. J. et al. Phase I study of samarium-153 lexidronam with docetaxel in castration-resistant metastatic prostate cancer. J. Clin. Oncol. 27, 2436-2442 (2009).

362. Tu, S. M. et al. Bone-targeted therapy for advanced androgen-independent carcinoma of the prostate: a randomised phase II trial. Lancet 357, 336-341 (2001).
363. Sciuto, R. et al. Effects of low-dose cisplatin on 89Sr therapy for painful bone metastases from prostate cancer: a randomized clinical trial. J. Nucl. Med $\mathbf{4 3}$, 79-86 (2002).

364. Fizazi, K. et al. Phase II trial of consolidation docetaxel and samarium-153 in patients with bone metastases from castration-resistant prostate cancer. J. Clin. Oncol. 27, 2429-2435 (2009).

365. Chow, E., Harris, K., Fan, G., Tsao, M. \& Sze, W. M. Palliative radiotherapy trials for bone metastases: a systematic review. J. Clin. Oncol. 25, 1423-1436 (2007).

366. McQuay, H. J., Carroll, D. \& Moore, R. A. Radiotherapy for painful bone metastases: a systematic review. Clin. Oncol. 9, 150-154 (1997).

367. $\mathrm{Wu}$, J. S. et al. Meta-analysis of dose-fractionation radiotherapy trials for the palliation of painful bone metastases. Int J. Radiat. Oncol. Biol. Phys. 55, 594-605 (2003).

368. Sze, W. M., Shelley, M. D., Held, I., Wilt, T. J. \& Mason, M. D. Palliation of metastatic bone pain: single fraction versus multifraction radiotherapy-a systematic review of randomised trials. Clin. Oncol. 15, 345-352 (2003).

369. Hartsell, W. F. et al. Randomized trial of short- versus long-course radiotherapy for palliation of painful bone metastases. J. Nat/ Cancer Inst. 97, 798-804 (2005).

370. Higinbotham, N. L. \& Marcove, R. C. The management of pathological fractures. J. Trauma 5, 792-798 (1965).

371. Coleman, R. E. Clinical features of metastatic bone disease and risk of skeletal morbidity. Clin. Cancer Res. 12, 6243s-6249s (2006).

372. Schulman, K. L. \& Kohles, J. Economic burden of metastatic bone disease in the U.S. Cancer 109, 2334-2342 (2007).

373. Forsberg, J. A., Eberhardt, J., Boland, P. J., Wedin, R. \& Healey, J. H. Estimating survival in patients with operable skeletal metastases: an application of a bayesian belief network. PLOS ONE 6, e19956 (2011).

374. Ratasvuori, M. et al. Prognostic role of en-bloc resection and late onset of bone metastasis in patients with bone-seeking carcinomas of the kidney, breast, lung, and prostate: SSG study on 672 operated skeletal metastases. J. Surg. Oncol. 110, 360-365 (2014)

375. Harvey, N., Ahlmann, E. R., Allison, D. C., Wang, L. \& Menendez, L. R. Endoprostheses last longer than intramedullary devices in proximal femur metastases. Clin. Orthop. Relat. Res. 470, 684-691 (2012).

376. Harrington, K. D. Orthopedic surgical management of skeletal complications of malignancy. Cancer 80, 1614-1627 (1997).

377. Facchini, G. et al. Palliative embolization for metastases of the spine. Eur. J. Orthop. Surg. Traumatol. 26, 247-252 (2016).

378. Rossi, G. et al. Embolisation of bone metastases from renal cancer. Radio. Med. 118, 291-302 (2013)

379. Cheung, F. H. The practicing orthopedic surgeon's guide to managing long bone metastases. Orthop. Clin. North Am. 45, 109-119 (2014).

380. Willeumier, J. J., van der Linden, Y. M., van de Sande, M. A. J. \& Dijkstra, P. D. S. Treatment of pathological fractures of the long bones. EFORT Open Rev. 1, 136-145 (2016).

381. Errani, C. et al. Treatment for long bone metastases based on a systematic literature review. Eur. J. Orthop. Surg. Traumatol. 27, 205-211 (2017).

382. Sun, G., Jin, P., Liu, X. W., Li, M. \& Li, L. Cementoplasty for managing painful bone metastases outside the spine. Eur. Radio. 24, 731-737 (2014).

383. Eisenberg, E., Shay, L., Keidar, Z., Amit, A. \& Militianu, D. Magnetic resonanceguided focused ultrasound surgery for bone metastasis: from pain palliation to biological ablation? J. Pain. Symptom Manag. 56, 158-162 (2018).

384. Hurwitz, M. D. et al. Magnetic resonance-guided focused ultrasound for patients with painful bone metastases: phase III trial results. J. Nat/ Cancer Inst. 106, dju082 (2014).

385. Liberman, B. et al. Pain palliation in patients with bone metastases using MRguided focused ultrasound surgery: a multicenter study. Ann. Surg. Oncol. 16, 140-146 (2009).

386. Gianfelice, D. et al. Palliative treatment of painful bone metastases with MR imaging-guided focused ultrasound. Radiology 249, 355-363 (2008).

387. Roelofs, A. J., Thompson, K., Gordon, S. \& Rogers, M. J. Molecular mechanisms of action of bisphosphonates: current status. Clin. Cancer Res. 12, 6222s-6230s (2006).

388. Lehenkari, P. P. et al. Further insight into mechanism of action of clodronate: inhibition of mitochondrial ADP/ATP translocase by a nonhydrolyzable, adenine-containing metabolite. Mol. Pharm. 61, 1255-1262 (2002).

389. Pickup, M. W., Owens, P. \& Moses, H. L. TGF- $\beta$, bone morphogenetic protein, and activin signaling and the tumor microenvironment. Cold Spring Harb Perspect Biol. 9(5), a022285, https://doi.org/10.1101/cshperspect.a022285 (2017).

390. Buijs, J. T., Stayrook, K. R. \& Guise, T. A. The role of TGF- $\beta$ in bone metastasis: Novel therapeutic perspectives. Bonekey Rep. 1, 96-705, https://doi.org/10.1038/ bonekey.2012.96 (2012).

391. Dalle Carbonare, L. et al. Bisphosphonates decrease telomerase activity and hTERT expression in MCF-7 breast cancer cells. Mol. Cell. Endocrinol. 240, 23-31 (2005). 
392. Van Poznak, C. et al. Expression of osteoprotegerin (OPG), TNF related apoptosis inducing ligand (TRAIL), and receptor activator of nuclear factor kappaB ligand (RANKL) in human breast tumours. J. Clin. Pathol. 59, 56-63 (2006).

393. Soltau, J. et al. Antitumoral and antiangiogenic efficacy of bisphosphonates in vitro and in a murine RENCA model. Anticancer Res. 28, 933-941 (2008).

394. Backman, U., Svensson, A., Christofferson, R. H. \& Azarbayjani, F. The bisphosphonate, zoledronic acid reduces experimental neuroblastoma growth by interfering with tumor angiogenesis. Anticancer Res. 28, 1551-1557 (2008).

395. Ribatti, D. et al. Clodronate inhibits angiogenesis in vitro and in vivo. Oncol. Rep. 19, 1109-1112 (2008).

396. Hashimoto, K. et al. Alendronate suppresses tumor angiogenesis by inhibiting Rho activation of endothelial cells. Biochem. Biophys. Res. Commun. 354, 478-484 (2007)

397. Tang, X. et al. Bisphosphonates suppress insulin-like growth factor 1-induced angiogenesis via the HIF-1alpha/VEGF signaling pathways in human breast cancer cells. Int. J. Cancer 126, 90-103 (2010).

398. Zhou, J. Z. et al. Osteocytic connexin hemichannels suppress breast cancer growth and bone metastasis. Oncogene 35, 5597-5607 (2016).

399. Mundy, G. R., Yoneda, T. \& Hiraga, T. Preclinical studies with zoledronic acid and other bisphosphonates: impact on the bone microenvironment. Semin Oncol. 28, 35-44 (2001).

400. Kokufu, I., Kohno, N., Yamamoto, M. \& Takao, S. Adjuvant pamidronate therapy prevents the development of bone metastases in breast cancer patients with four or more positive nodes. Oncol. Lett. 1, 247-252 (2010).

401. Lipton, A. et al. Pamidronate prevents skeletal complications and is effective palliative treatment in women with breast carcinoma and osteolytic bone metastases: long term follow-up of two randomized, placebo-controlled trials. Cancer 88, 1082-1090 (2000).

402. Berenson, J. R. et al. Zoledronic acid reduces skeletal-related events in patients with osteolytic metastases. Cancer 91, 1191-1200 (2001).

403. Rosen, L. S. et al. Zoledronic acid versus pamidronate in the treatment of skeletal metastases in patients with breast cancer or osteolytic lesions of multiple myeloma: a phase III, double-blind, comparative trial. Cancer J. 7, 377-387 (2001).

404. Atula, S. et al. Extended safety profile of oral clodronate after long-term use in primary breast cancer patients. Drug Saf. 26, 661-671 (2003).

405. Powles, T. et al. Reduction in bone relapse and improved survival with ora clodronate for adjuvant treatment of operable breast cancer [ISRCTN83688026]. Breast Cancer Res. 8, R13 (2006).

406. Dearnaley, D. P. et al. A double-blind, placebo-controlled, randomized trial of oral sodium clodronate for metastatic prostate cancer (MRC PR05 Trial). J. Nat/ Cancer Inst. 95, 1300-1311 (2003).

407. Saad, F. et al. A randomized, placebo-controlled trial of zoledronic acid in patients with hormone-refractory metastatic prostate carcinoma. J. Natl Cancer Inst. 94, 1458-1468 (2002)

408. Higano, C. S. Understanding treatments for bone loss and bone metastases in patients with prostate cancer: a practical review and guide for the clinician. Urol. Clin. North Am. 31, 331-352 (2004).

409. Khosla, S. et al. Bisphosphonate-associated osteonecrosis of the jaw: report of a task force of the American Society for Bone and Mineral Research. J. Bone Miner Res. 22, 1479-1491 (2007).

410. Woo, S. B., Hellstein, J. W. \& Kalmar, J. R. Narrative [corrected] review: bisphosphonates and osteonecrosis of the jaws. Ann. Intern. Med. 144, 753-761 (2006).

411. Rodriguez-Lozano, F. J. \& Onate-Sanchez, R. E. Treatment of osteonecrosis of the jaw related to bisphosphonates and other antiresorptive agents. Med. Oral Patol. Oral Cir. Bucal 21, e595-e600 (2016).

412. Neville-Webbe, H. L., Rostami-Hodjegan, A., Evans, C. A., Coleman, R. E. \& Holen, I. Sequence- and schedule-dependent enhancement of zoledronic acid induced apoptosis by doxorubicin in breast and prostate cancer cells. Int. J. Cancer 113 364-371 (2005).

413. Winter, M. C., Holen, I. \& Coleman, R. E. Exploring the anti-tumour activity of bisphosphonates in early breast cancer. Cancer Treat. Rev. 34, 453-475 (2008).

414. Kurabayashi, A. et al. Combination with third-generation bisphosphonate (YM529) and interferon-alpha can inhibit the progression of established bone renal cell carcinoma. Cancer Sci. 106, 1092-1099 (2015).

415. Stopeck, A. T. et al. Denosumab compared with zoledronic acid for the treatment of bone metastases in patients with advanced breast cancer: a randomized, double-blind study. J. Clin. Oncol. 28, 5132-5139 (2010).

416. Fizazi, K. et al. Denosumab versus zoledronic acid for treatment of bone metastases in men with castration-resistant prostate cancer: a randomised, double-blind study. Lancet 377, 813-822 (2011).

417. Lipton, A. \& Goessl, C. Clinical development of anti-RANKL therapies for treatment and prevention of bone metastasis. Bone 48, 96-99 (2011).
418. Schieferdecker, A. et al. Denosumab mimics the natural decoy receptor osteoprotegerin by interacting with its major binding site on RANKL. Oncotarget $\mathbf{5}$, 6647-6653 (2014)

419. Liu, Y. et al. AB0078|Role of IL-8 and Its Receptor in Anti-Citrullinated Protein Antibody Mediated Osteoclastogenesis in RA. Ann. Rheum. Dis. 75, 923 (2016).

420. Duda, D. G. et al. CXCL12 (SDF1alpha)-CXCR4/CXCR7 pathway inhibition: an emerging sensitizer for anticancer therapies? Clin. Cancer Res. 17, 2074-2080 (2011).

421. Batchelor, T. T. et al. AZD2171, a pan-VEGF receptor tyrosine kinase inhibitor normalizes tumor vasculature and alleviates edema in glioblastoma patients. Cancer Cell 11, 83-95 (2007).

422. Batchelor, T. T. et al. Phase II study of cediranib, an oral pan-vascular endothelial growth factor receptor tyrosine kinase inhibitor, in patients with recurrent glioblastoma. J. Clin. Oncol. 28, 2817-2823 (2010).

423. di Tomaso, E. et al. Glioblastoma recurrence after cediranib therapy in patients: lack of "rebound" revascularization as mode of escape. Cancer Res. 71, 19-28 (2011).

424. Kamoun, W. S. et al. Edema control by cediranib, a vascular endothelial growth factor receptor-targeted kinase inhibitor, prolongs survival despite persistent brain tumor growth in mice. J. Clin. Oncol. 27, 2542-2552 (2009).

425. Hiratsuka, S. et al. C-X-C receptor type 4 promotes metastasis by activating p38 mitogen-activated protein kinase in myeloid differentiation antigen (Gr-1)positive cells. Proc. Natl Acad. Sci. USA 108, 302-307 (2011).

426. Shaked, Y. et al. Rapid chemotherapy-induced acute endothelial progenitor cell mobilization: implications for antiangiogenic drugs as chemosensitizing agents. Cancer Cell 14, 263-273 (2008).

427. Shaked, Y. et al. Contribution of granulocyte colony-stimulating factor to the acute mobilization of endothelial precursor cells by vascular disrupting agents. Cancer Res. 69, 7524-7528 (2009).

428. Kozin, S. V. et al. Recruitment of myeloid but not endothelial precursor cells facilitates tumor regrowth after local irradiation. Cancer Res. 70, 5679-5685 (2010).

429. Kioi, M. et al. Inhibition of vasculogenesis, but not angiogenesis, prevents the recurrence of glioblastoma after irradiation in mice. J. Clin. Investig. 120, 694-705 (2010).

430. Chang, C. C. et al. Dose-dependent effect of radiation on angiogenic and angiostatic CXC chemokine expression in human endothelial cells. Cytokine $\mathbf{4 8}$ 295-302 (2009).

431. Padua, D. et al. TGFbeta primes breast tumors for lung metastasis seeding through angiopoietin-like 4. Cell 133, 66-77 (2008).

432. Tan, A. R., Alexe, G. \& Reiss, M. Transforming growth factor-beta signaling: emerging stem cell target in metastatic breast cancer? Breast Cancer Res. Treat 115, 453-495 (2009).

433. Biswas, S. et al. Anti-transforming growth factor ss antibody treatment rescues bone loss and prevents breast cancer metastasis to bone. PLOS ONE 6, e27090 (2011).

434. Ganapathy, V. et al. Targeting the transforming growth factor-beta pathway inhibits human basal-like breast cancer metastasis. Mol. Cancer 9, 122 (2010).

435. Dasch, J. R., Pace, D. R., Waegell, W., Inenaga, D. \& Ellingsworth, L. Monoclonal antibodies recognizing transforming growth factor-beta. Bioactivity neutralization and transforming growth factor beta 2 affinity purification. J. Immunol. 142 1536-1541 (1989).

436. Andrade, S. E., Donahue, J. G., Chan, K. A., Watson, D. J. \& Platt, R. Liver function testing in patients on HMG-CoA reductase inhibitors. Pharmacoepidemiol. Drug Saf. 12, 307-313 (2003).

437. Wong, W. W., Dimitroulakos, J., Minden, M. D. \& Penn, L. Z. HMG-CoA reductase inhibitors and the malignant cell: the statin family of drugs as triggers of tumorspecific apoptosis. Leukemia 16, 508-519 (2002).

438. Liu, C. M. et al. In vivo targeting of ADAM9 gene expression using lentivirusdelivered shRNA suppresses prostate cancer growth by regulating REG4 dependent cell cycle progression. PLOS ONE 8, e53795 (2013).

439. Mandal, C. C., Ghosh-Choudhury, N., Yoneda, T., Choudhury, G. G. \& GhoshChoudhury, N. Simvastatin prevents skeletal metastasis of breast cancer by an antagonistic interplay between p53 and CD44. J. Biol. Chem. 286, 11314-11327 (2011).

440. Asanuma, K. et al. The thrombin inhibitor, argatroban, inhibits breast cancer metastasis to bone. Breast Cancer 20, 241-246 (2013).

441. Nelson, J. B. et al. Suppression of prostate cancer induced bone remodeling by the endothelin receptor A antagonist atrasentan. J. Urol. 169, 1143-1149 (2003).

442. $\mathrm{Pu}, \mathrm{R}$. et al. Rapid bone repair in a patient with lung cancer metastases to the spine using a novel herbal medicine: A case report. Oncol. Lett. 12, 2023-2027 (2016).

443. Mandal, C. C., Ghosh-Choudhury, T., Yoneda, T., Choudhury, G. G. \& GhoshChoudhury, N. Fish oil prevents breast cancer cell metastasis to bone. Biochem. Biophys. Res. Commun. 402, 602-607 (2010). 
444. Dalrymple, S. L., Becker, R. E. \& Isaacs, J. T. The quinoline-3-carboxamide antiangiogenic agent, tasquinimod, enhances the anti-prostate cancer efficacy of androgen ablation and taxotere without effecting serum PSA directly in human xenografts. Prostate 67, 790-797 (2007).

445. Isaacs, J. T. et al. Identification of ABR-215050 as lead second generation quinoline-3-carboxamide anti-angiogenic agent for the treatment of prostate cancer. Prostate 66, 1768-1778 (2006).

446. Isaacs, J. T. The long and winding road for the development of tasquinimod as an oral second-generation quinoline-3-carboxamide antiangiogenic drug for the treatment of prostate cancer. Expert Opin. Investig. Drugs 19, 1235-1243 (2010).

447. Bratt, O. et al. Open-label, clinical phase I studies of tasquinimod in patients with castration-resistant prostate cancer. Br. J. Cancer 101, 1233-1240 (2009).

448. Jennbacken, K. et al. Inhibition of metastasis in a castration resistant prostate cancer model by the quinoline-3-carboxamide tasquinimod (ABR-215050). Prostate 72, 913-924 (2012).

449. Shukeir, N. et al. Pharmacological methyl group donors block skeletal metastasis in vitro and in vivo. Br. J. Pharmacol. 172, 2769-2781 (2015).

450. Petrel, $\mathrm{C}$. et al. Positive and negative allosteric modulators of the $\mathrm{Ca}^{2+}$-sensing receptor interact within overlapping but not identical binding sites in the transmembrane domain. J. Biol. Chem. 279, 18990-18997 (2004).

451. Chang, W. et al. Complex formation with the Type B gamma-aminobutyric acid receptor affects the expression and signal transduction of the extracellular calcium-sensing receptor. Studies with HEK-293 cells and neurons. J. Biol. Chem. 282, 25030-25040 (2007).

452. Kumar, S. et al. An orally active calcium-sensing receptor antagonist that transiently increases plasma concentrations of PTH and stimulates bone formation. Bone 46, 534-542 (2010).

453. Henry, J. G., Mitnick, M., Dann, P. R. \& Stewart, A. F. Parathyroid hormone-related protein-(1-36) is biologically active when administered subcutaneously to humans. J. Clin. Endocrinol. Metab. 82, 900-906 (1997).
454. Horwitz, M. J. et al. Parathyroid hormone-related protein for the treatment of postmenopausal osteoporosis: defining the maximal tolerable dose. J. Clin. Endocrinol. Metab. 95, 1279-1287 (2010).

455. Mooberry, S. L. New insights into 2-methoxyestradiol, a promising antiangiogenic and antitumor agent. Curr. Opin. Oncol. 15, 425-430 (2003).

456. Mabjeesh, N. J. et al. $2 \mathrm{ME} 2$ inhibits tumor growth and angiogenesis by disrupting microtubules and dysregulating HIF. Cancer Cell 3, 363-375 (2003).

457. Mooberry, S. L. Mechanism of action of 2-methoxyestradiol: new developments. Drug Resist. Updat. 6, 355-361 (2003).

458. Tinley, T. L. et al. Novel 2-methoxyestradiol analogues with antitumor activity. Cancer Res. 63, 1538-1549 (2003).

459. Powis, G. \& Kirkpatrick, L. Hypoxia inducible factor-1alpha as a cancer drug target. Mol. Cancer Ther. 3, 647-654 (2004).

460. Melillo, G. Inhibiting hypoxia-inducible factor 1 for cancer therapy. Mol. Cancer Res. 4, 601-605 (2006).

(i) Open Access This article is licensed under a Creative Commons By Attribution 4.0 International License, which permits use, sharing, adaptation, distribution and reproduction in any medium or format, as long as you give appropriate credit to the original author(s) and the source, provide a link to the Creative Commons license, and indicate if changes were made. The images or other third party material in this article are included in the article's Creative Commons license, unless indicated otherwise in a credit line to the material. If material is not included in the article's Creative Commons license and your intended use is not permitted by statutory regulation or exceeds the permitted use, you will need to obtain permission directly from the copyright holder. To view a copy of this license, visit http://creativecommons. org/licenses/by/4.0/.

(c) The Author(s) 2020 